
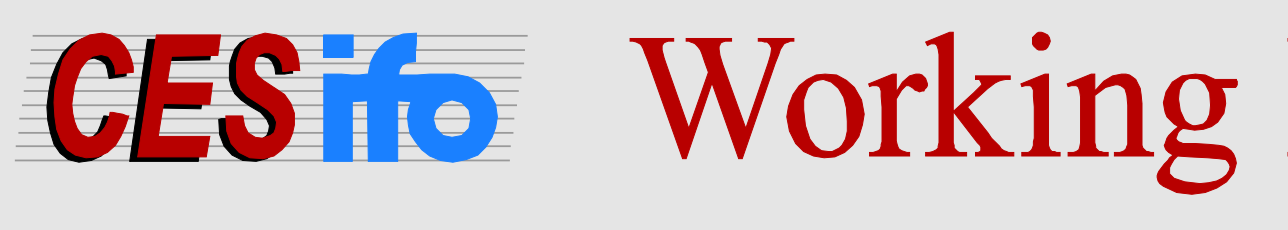

Papers

www.cesifo.org/wp

\title{
Measuring Strategic Firm Interaction in Product-Quality Choices: The Case of Airline Flight Frequency
}

\author{
Jan K. Brueckner \\ Dan Luo
}

CESIFO WORKING PAPER NO. 4066

CATEGORY 11: INDUSTRIAL ORGANISATION

JANUARY 2013

An electronic version of the paper may be downloaded

- from the SSRN website:

- from the RePEc website:

- from the CESifo website:

wWw.SSRN.com

www.RePEc.org

www.CESifo-group.org/wp

\section{CESifo}




\title{
Measuring Strategic Firm Interaction in Product-Quality Choices: The Case of Airline Flight Frequency
}

\begin{abstract}
This paper investigates strategic interaction among airlines in product-quality choices. Using an instrumental variables approach, the paper estimates flight-frequency reaction functions, which relate an airline's frequency on a route to its own characteristics and to the frequencies of competing airlines. A positive reaction function slope is found in some cases, indicating the presence of strategic interaction in the choice of frequencies. The paper also asks whether multimarket contact generates mutual forbearance in frequency competition, finding no evidence for such an effect.
\end{abstract}

JEL-Code: L100, L930.

Keywords: airlines, reaction function, product quality, flight frequency.

Jan K. Brueckner Department of Economics University of California, Irvine 3151 Social Science Plaza USA - Irvine, CA 92697

jkbrueck@uci.edu
Dan Luo

Department of Economics

University of California, Irvine

3151 Social Science Plaza

USA - Irvine, CA 92697

dluo1@uci.edu

December 2012 


\title{
Measuring Strategic Firm Interaction in Product-Quality Choices: The Case of Airline Flight Frequency
}

by

\author{
Jan K. Brueckner and Dan Luo*
}

\section{Introduction}

A voluminous theoretical literature deals with product differentiation and the choice of product quality. Horizontal product differentiation, where products have no natural quality ordering, is usually analyzed in a spatial-competition setting in the Hotelling tradition, with important contributions by d'Aspremont et al. (1979) and Salop (1979). Alternatively, Gabszewicz and Thisse (1979), Shaked and Sutton (1982) and other authors study vertical product differentiation, where products are ordered by quality and consumers have different quality valuations.

Despite the existence of this large theoretical literature, empirical work on product-quality competition is scarce. The purpose of this paper is to remedy this shortage by providing an empirical analysis of quality competition between firms, with a focus on the airline industry. The analysis studies what is probably the most important dimension of the quality of airline service: flight frequency. The importance of frequency was first shown empirically in the work of Morrison and Winston (1995), who use a multinomial logit model to analyze airline choices by passengers. In addition to finding that choices are influenced by fares and other elements of service quality, Morrison and Winston show that frequent daily departures by a given airline on a route strongly influence travelers to choose it. More recently, the structural demand estimates of Berry and Jia (2010) again show that flight frequency is highly valued by consumers. ${ }^{1}$

Unlike existing empirical work on product-quality determination, which is structural in nature and is discussed below, the paper attempts to measure the strength of strategic interaction in quality choices by airlines. It does so by estimating flight-frequency reaction functions, which give a carrier's best frequency response to a competitor's frequency choice. A statis- 
tically significant slope coefficient provides evidence that strategic interaction occurs when airlines choose flight frequencies, and the magnitude of the coefficient indicates its strength. The competitor's frequency, which appears on the right-hand side of the reaction function along with carrier and route characteristics, is an endogenous variable, being jointly determined along with the carrier's own frequency in a Cournot-Nash equilibrium. Therefore, an instrumental variables approach is needed to generate a consistent estimate of the reaction function's slope.

Estimation of reaction functions is the focus of empirical work in a number of fields of economics. In public economics, the tax competition literature contains many studies that estimate reaction functions. Strategic interaction arises because tax rates in competing jurisdictions must be taken into account when a given jurisdiction chooses its own rate, recognizing that capital and labor migrate in response to tax-rate differentials. See Brueckner (2003) and Revelli (2005) for surveys of this literature. In addition, reaction functions are sometimes estimated in the literature on peer effects, where an individual's choice of the level of some decision variable depends on peer choices. Dietz (2002) and Dujardin, Peeters and Thomas (2009) provide detailed surveys of the peer-effects literature. In both types of studies, the endogeneity of the peer's or the competing jurisdiction's choice must be taken into account in the estimation, an econometric problem that is analyzed by Manski (1993).

Estimation of reaction functions is, by contrast, less common in the industrial organization literature. Price reaction functions are estimated in some papers as part of a procedure for deriving conjectual variations, which give a rival firm's anticipated response when a firm changes its price or output (see Liang (1989) and Dhar et al. (2005)). ${ }^{2}$ Many studies that estimate price reaction functions can also be found in the marketing literature, with contributions by Lazzarini et al. (2006) (who focus on the auto insurance industry), Reimer (2004) (who studies the ready-to-eat cereal industry), Cotterill et al. (2000) (who analyze the market for private label and branded grocery products) and Vickner and Davies (1999) (who study the spaghetti sauce industry).

Although distinguished by its focus on reaction functions, the present paper is related to a number of recent empirical studies analyzing the choice of product quality using structural 
models. The early structural literature (Berry (1994), Berry, Levinsohn and Pakes (1995)) treats product attributes as exogenous, but recent empirical models have portrayed firms as choosing product quality along with price. In the models of Crawford, Shcherbakov and Shum (2011) and Fan (2011), firms choose the levels of continuous measures of product quality (for newspapers and cable television, respectively), while firms in Draganski, Mazzeo and Seim (2009) choose which product varieties to offer (the empirical work focuses on ice cream flavors). In each case, the empirical exercise yields estimates of taste and cost parameters, which are used in the latter two papers to simulate the effects of mergers on product quality or variety. ${ }^{3}$ By contrast, the estimated reaction functions in this paper do not identify underlying utility and production parameters, which are intermixed in the slope coefficient. ${ }^{4}$ Instead, the goal of the paper is to measure the strength of strategic interaction, with the slope of the airline reaction function of interest in itself, not the values of the underlying parameters.

To motivate the empirical analysis, the paper reviews the theoretical frequency-competition model of Brueckner (2010). To avoid the complexity of the spatial-competition approach, which is used by Schipper, Nijkamp and Rietveld (2003, 2007) and Lindsey and Tomaszewska (1999) to study frequency competition, Brueckner's approach assumes that consumers must choose an airline before knowing their preferred departure times. As a result, a carrier's average flight frequency is what matters (along with the fare) in the choice between airlines, not the departure times of individual flights. Despite the resulting elimination of space, the model effectively involves horizontal competition in the Hotelling tradition, with exogenous brand loyalty to individual carriers providing a choice friction analogous to the spatial friction in the Hotelling model. In contrast to this approach, Borenstein and Netz (1999) carry out an empirical analysis whose focus is the departure times of individual flights rather than overall frequencies, and they rely on a spatial competition model to motivate the analysis. Their goal is to identify market characteristics that lead to greater clustering of departure times for different carriers. ${ }^{5}$

Data for the estimation of flight-frequency reaction functions is readily available from government sources, which tabulate monthly airline departures on each nonstop route. Variables that shift a carrier's reaction function include route characteristics (distance, endpoint popula- 
tions and incomes, a leisure-destination endpoint) as well as carrier characteristics, as captured by dummy variables indicating airline identities. The hub status of the route endpoints for the airline is another such characteristic. As noted above, the endogeneity of the competitor's frequency requires the use of instruments in estimating the reaction function, and the theoretical structure helps in choosing appropriate variables. The chosen instruments are the vector of carrier dummy variables for the competing carrier, which shift that carrier's reaction function and thus help determine its own frequency. These variables are used in two-stage least squares estimation of the reaction function, and a statistically significant slope coefficient in the second-stage regression is evidence of strategic interaction. An insignificant slope coefficient, on the other hand, suggests that interaction is not present in the choice of flight frequencies. ${ }^{6}$

The estimation is carried out for nonstop duopoly routes. With only two carriers present, interaction is more straightforward on such routes than on oligopoly routes. A pooled regression is carried out first, where LCCs (low-cost carriers) are not distinguished from legacy carriers. Since the coefficient of the reaction function might depend on the nature of the competitor, the pooled duopoly regression is supplemented with regressions focusing on legacy-legacy, LCCLCC, and legacy-LCC duopolies.

In an extension of basic model, the paper also asks whether multimarket contact shifts the frequency reaction function. Evans and Kessides (1994), Zou, Dresner and Windle (2011) and others study the effect of multimarket contact on fares, finding that airlines show mutual forebearance by pricing less aggressively on routes where multimarket contact with the competitors is high (fearing retaliatory behavior on other jointly contested routes). The question is whether such behavior extends to frequencies. ${ }^{7}$

Several conclusions emerge from the empirical analysis. First, the slope of the reaction function is positive when the two duopoly carriers are of the same type. That is, frequencies are strategic complements in duopolies involving two legacy carriers or two LCCs. Second, on duopoly routes where carriers are of different types, weak performance of the carrier-dummy instruments prevents definitive conclusions from being reached. Therefore, while the empirical analysis shows the presence of strategic frequency interaction within carrier types, no conclusion can be drawn regarding interaction across types. Third, analysis of the effect of multimarket 
contact suggests no evidence of mutual forbearance in the choice of flight frequencies within carrier types.

The remainder of the paper is organized as follows. Section 2 provides the theoretical framework. Section 3 presents the empirical model and discusses the data and construction of the variables. Section 4 presents the main results, and section 5 introduces multimarket contact. Section 6 illustrates how the results might be used to predict the effect of a change in the airline operating environment, and section 7 offers conclusions.

\section{Theoretical Framework}

This section of the paper serves to motivate the empirical work by deriving a flightfrequency reaction function like those estimated below from a theoretical model, drawing on the framework of Brueckner (2010). The model focuses on a single transport market connecting two cities. Passengers in the market have mass $M$, and the market is served by $n$ competing carriers, with $n$ set equal to two given the duopoly focus. Carrier $i$ operates $f_{i}$ flights that are evenly spaced around a circle representing departure times, with $i=1,2$. A crucial feature of the model is that a consumer chooses a carrier before knowing his preferred departure time, which is drawn from a uniform distribution on the circle. As a result, a carrier's flight frequency is all that matters, not the departure times of individual flights.

Letting $T$ denote the circle's time circumference, the interval between carrier 1's flights is $T / f_{1}$. Since the largest gap between a flight and a preferred departure time is $T / 2 f_{1}$, the expected schedule delay (the difference between the preferred and nearest departure time) for a consumer choosing carrier 1 is $T / 4 f_{1}$. Letting $v$ denote the cost per unit of schedule-delay time, $v T / 4 f_{1} \equiv \gamma / f_{1}$ is the cost of schedule delay, where $\gamma \equiv v T / 4$. With $p_{1}$ denoting the carrier's fare, the full price of travel on carrier 1 is then $p_{1}+\gamma / f_{1}$. This full price depends on the fare, a price variable, as well as frequency, a quality variable chosen by the carrier.

Consumers value consumption, denoted $x$, and trips, denoted $t$. If the consumer chooses carrier 1 , then utility is given by $U\left(x, a_{1} t\right)$, where the $a_{1}$ factor measures the degree of brand loyalty to carrier 1 (travel on carrier 2 generates utility $U\left(x, a_{2} t\right)$ ). Brand loyalty is exogenous and consumer-specific, with each consumer having particular values of $a_{1}$ and $a_{2}$. Loyalty 
provides a friction in the competitive market, so that a carrier is able to attract its most loyal customers even when its fare is relatively high or its frequency low.

The consumer's budget constraint is given by

$$
x+\left(p_{1}+\gamma / f_{1}\right) t=y,
$$

where $y$ is income, and preferences are of the Cobb-Douglas form:

$$
U\left(x, a_{1} t\right)=x^{1-\beta}\left(a_{1} t\right)^{\beta} .
$$

Maximizing utility subject to the budget constraint gives

$$
t=\frac{\beta y}{p_{1}+\gamma / f_{1}}, \quad x=(1-\beta) y .
$$

The consumer's indirect utility function for travel on carrier 1 can then be written as

$$
\begin{aligned}
V\left(\frac{p_{1}+\gamma / f_{1}}{a_{1}}, y\right) & \equiv(y(1-\beta))^{1-\beta}\left(\frac{a_{1} \beta y}{p_{1}+\gamma / f_{1}}\right)^{\beta} \\
& =\kappa y\left(\frac{p_{1}+\gamma / f_{1}}{a_{1}}\right)^{-\beta}
\end{aligned}
$$

where $\kappa \equiv(1-\beta)^{1-\beta} \beta^{\beta}$. Note that, since the brand-loyalty parameter $a_{1}$ appears multiplicatively in preferences, it does not affect the $t$ and $x$ solutions in (3) but does shift the indirect utility function.

For the passenger to choose carrier 1 over carrier $2, V_{1} \geq V_{2}$ is required, so that

$$
V\left(\frac{p_{1}+\gamma / f_{1}}{a_{1}}, y\right) \geq V\left(\frac{p_{2}+\gamma / f_{2}}{a_{2}}, y\right) \quad \text { or } \quad a_{2} \leq \frac{a_{1}\left(p_{2}+\gamma / f_{2}\right)}{p_{1}+\gamma / f_{1}}
$$

For given fares and frequencies, a consumer's brand loyalty to carrier 2 must therefore be sufficiently small relative to $a_{1}$ in order for carrier 1 to be chosen. 
The total number of travelers who prefer carrier 1 depends on the distribution of brand loyalty, given by $\phi\left(a_{1}, a_{2}\right)$. A symmetric, uniform distribution is assumed, so that $\phi\left(a_{1}, a_{2}\right)=$ $M / \alpha^{2}$, where $a_{1}, a_{2} \in[0, \alpha]$. The number of travelers who prefer carrier 1 is given by the integral of $\phi$ over the region specified in (5), while the carrier's passenger volume, denoted $q_{1}$, is the integral of this density weighted by the chosen trip volumes from (3). The expression for $q_{1}$ is thus

$$
\begin{aligned}
q_{1} & =\frac{\beta y}{p_{1}+\gamma / f_{1}} \int_{a_{1}=0}^{\alpha} \int_{a_{2}=0}^{\frac{a_{1}\left(p_{2}+\gamma / f_{2}\right)}{p_{1}+\gamma / f_{1}}} \frac{M}{\alpha^{2}} d a_{1} d a_{2} \\
& =\frac{\mu\left(p_{2}+\gamma / f_{2}\right)}{2\left(p_{1}+\gamma / f_{1}\right)^{2}}
\end{aligned}
$$

where $\mu=\beta y M$ is a market-size parameter, which depends on the trip utility exponent, income and the passenger mass, all of which affect the aggregate demand for trips. Note that $q_{1}$ in $(5)$ is a function of fares $\left(p_{1}\right.$ and $\left.p_{2}\right)$ and frequencies $\left(f_{1}\right.$ and $\left.f_{2}\right)$ for both carriers.

Letting $s_{1}$ denote seats per departure, cost per flight is given by $\theta+\tau s_{1}$, reflecting a fixed cost of $\theta$ and a marginal seat cost of $\tau$. Note that the presence of the fixed cost provides a source of increasing returns at the individual flight level, and that aircraft size is assumed not to affect consumer utility, thus not being an element of service quality. The carrier's total cost can then be written as

$$
f_{1}\left(\theta+\tau s_{1}\right)=\theta f_{1}+\tau q_{1}
$$

using the fact that total seats, $f_{1} s_{1}$, must equal passenger volume $q_{1}$. Using (6) and (7), profit is then given by

$$
\begin{aligned}
\pi_{1} & =\left(p_{1}-\tau\right) q_{1}-\theta f_{1} \\
& =\frac{\left(p_{1}-\tau\right) \mu\left(p_{2}+\gamma / f_{2}\right)}{2\left(p_{1}+\gamma / f_{1}\right)^{2}}-\theta f_{1}
\end{aligned}
$$

Carrier 1's goal is to choose frequency and the fare to maximize profit, taking the choices of its competitor as given. Although Brueckner (2010) analyzed simultaneous choice, it is useful 
to instead view the carriers as playing a two-stage game, with frequencies chosen in the first stage and the fares chosen conditional on frequencies in the second stage, an order that makes sense given that fares are more easily adjusted than frequencies. Maximizing profit by choice of $p_{1}$ gives the first-order condition

$$
p_{1}=2 \tau+\gamma / f_{1}
$$

This solution shows that carrier 1 's second stage choice of $p_{1}$ is actually independent of carrier 2 's fare $\left(p_{2}\right)$ and frequency $\left(f_{2}\right)$, variables that would normally appear along with $f_{1}$ on the right-hand side of an equation like (9). The second-stage price equilibrium would then be determined by simultaneous solution of such an equation and its counterpart for carrier 2 (yielding $p_{1}$ and $p_{2}$ as functions of $f_{1}$ and $f_{2}$ ). But (9) directly gives $p_{1}$ as a function of $f_{1}$ alone, a simplification that is due to the model's particular structure. ${ }^{8}$

Plugging $p_{1}$ from (9) into the profit function, profit can be rewritten as

$$
\pi_{1}=\frac{\mu\left(\frac{\gamma+f_{2} \tau}{f_{2}}\right)}{4\left(\frac{\gamma+f_{1} \tau}{f_{1}}\right)}-\theta f_{1}
$$

Computing the first-order condition for $f_{1}$ and solving yields

$$
f_{1}=-\frac{\gamma}{\tau}+\frac{1}{2} \sqrt{\frac{\gamma \mu\left(\tau+\gamma / f_{2}\right)}{\theta \tau^{2}}} .
$$

This is the reaction function, which gives carrier 1's best response to carrier 2's frequency choice. Since $f_{2}$ appears in reciprocal form, the reaction function is downward sloping, implying that frequencies are strategic substitutes. Note that the slope varies with $f_{2}$ but also depends on all the parameters of the model.

It is important to recognize that the slope's negative sign is conditional on the particular structure of the current model. To derive a general expression for the slope of carrier 1's reaction function, let $\pi_{1}\left(f_{1}, f_{2}, p_{1}, p_{2}\right)$ denote the carrier's profit as a function of frequencies 
and fares, and let $p_{1}\left(f_{1}, f_{2}\right)$ and $p_{2}\left(f_{1}, f_{2}\right)$ denote the second-stage fare solutions conditional on frequencies. Substituting, profit can then be written as

$$
\tilde{\pi}_{1}\left(f_{1}, f_{2}\right) \equiv \pi_{1}\left[f_{1}, f_{2}, p_{1}\left(f_{1}, f_{2}\right), p_{2}\left(f_{1}, f_{2}\right)\right]
$$

The first-order condition for choice of $f_{1}$ is $\partial \widetilde{\pi}_{1} / \partial f_{1}=0$, and totally differentiating this condition yields the slope of carrier 1's reaction function:

$$
\frac{\partial f_{1}}{\partial f_{2}}=-\frac{\partial^{2} \widetilde{\pi}_{1} / \partial f_{1} f_{2}}{\partial^{2} \widetilde{\pi}_{1} / \partial f_{1}^{2}}
$$

Since the denominator of (13) must be negative for the second-order condition to be satisfied, the slope will take the sign of the cross-partial derivative in the numerator. This derivative, however, will be a very complicated expression, as can be seen by referring to (12), and its sign will generally be ambiguous and dependent on the detailed structure of the model. The negative slope in (11) is thus by no means general, with a different model structure potentially yielding an upward-sloping reaction function. Given this lack of generality, the current analysis should be viewed as only providing an example of how an explicit frequency reaction function can be derived in a full theoretical model, a demonstration that helps to motivate the ensuing empirical work. ${ }^{9}$ A final point is that, while (11) is derived under the assumption that the two firms are identical, the empirical reaction functions are allowed to differ across firms.

\section{Empirical Model and Data}

\subsection{Empirical Model}

The empirical analysis focuses on nonstop duopoly routes within the US. Flight frequency for connecting trips is a less straightforward concept (involving layover times), which justifies the nonstop focus. Estimation of the reaction function uses the following log-linear regression model:

$$
\operatorname{lnFREQ_{im}}=\alpha+\delta \operatorname{lnFREQ_{-im}}+\sigma X_{m}+\eta Z_{i m}+\epsilon_{i m}
$$


where $m$ denotes the route and $i$ denotes the $i$ th carrier serving it, with $i=1,2$ for the duopoly case. $\ln F R E Q_{i m}$ is the $\log$ frequency of carrier $i$ on nonstop route $m$ and $\ln F R E Q_{-i m}$ gives the $\log$ frequency of $i$ 's competitor, carrier $-i . X_{m}$ is a vector of route-characteristics variables including distance, endpoint incomes and populations, and a variable indicating a leisure route. $Z_{i m}$ represents carrier characteristics, which are mainly captured by a vector $D_{i m}$ of dummy variables representing carrier identities, with the variable corresponding to carrier $i$ turned on and the rest set equal to zero. These dummies capture cost differences across carriers as well as other idiosyncratic factors that affect frequency choices. Note that changes in $X_{m}$ and $D_{i m}$ shift the reaction function in a parallel fashion. Observe also that the log-linear model in (14) represents an approximation to a possibly more-complex functional form, such as the nonlinear relationship in (11). As a robustness check, results are also reported for a linear version of (14).

To understand estimation of (14), consider the set of legacy-legacy duopoly routes, where two legacies alone compete with one another. A reaction function is estimated for this legacylegacy subsample, as well as for other subsamples, as discussed in more detail below. Each legacy-legacy route has two observations, one for each legacy competitor, with the frequency values on the two sides of (14) switched between the observations but with the value of $X_{m}$ common between them. To estimate the reaction function for legacy-legacy competition, the regression is run on this set of observations.

Eq. (14) and its counterpart for carrier $-i$ constitute the two structural equations of a simultaneous-equations system, which consists of the reaction functions for carriers $i$ and $-i$. The solution to this system, which corresponds to the intersection of the two reaction functions, yields values for $\ln F R E Q_{i m}$ and $\ln F R E Q_{-i m}$. The right-hand-side variable $\ln F R E Q_{-i m}$ in (14) is thus endogenous, which means that consistent estimation requires the use of instruments. Proper instruments, used to generate predicted values of $\ln F R E Q_{-i m}$ in a two-stage least squares procedure, are the $D$ variables that give carrier identities, but with values that pertain to $i$ 's competitor, carrier $-i$. Observe that these variables are excluded from (14), making them suitable instruments in a simultaneous-equations setting. More generally, because they can be expected to satisfy relevance and exogeneity requirements, the competitor 
dummies are good instruments. First, along with the dummies $D_{i m}$ for carrier $i$ itself, the competitor dummies $\left(D_{-i m}\right)$ affect equilibrium frequencies for both carriers by determining the position of carrier $-i$ 's reaction function. As a result, they are correlated with carrier $-i$ 's frequency. Second, the competitor dummies are not likely to be correlated with unobservables that influence the position of carrier $i$ 's reaction function (components of $\epsilon_{i m}$ from (14)). In other words, the identify of the other carrier competing in the market is not likely to be correlated with unobservables that affect a given carrier's frequency choice. This claim is further discussed and justified below. Note finally that, since the reaction function in (14) has one endogenous right-hand side variable while the excluded vector $D_{-i m}$ consists of more than one dummy variable, the equation is overidentified.

The first-stage regression of two-stage least squares corresponds to the reduced-form equation for carrier $-i$, generated by the structural system in (14). Ignoring for the moment the other variables in $Z$ (considering only the carrier dummies), this equation is

$$
\operatorname{lnFREQ-im}=\zeta+\nu X_{m}+\rho D_{i m}+\lambda D_{-i m}+\xi_{-i m}
$$

where

$$
\zeta=\frac{\alpha}{1-\delta}, \quad \nu=\frac{\sigma}{1-\delta}, \quad \rho=\frac{\delta \eta}{1-\delta^{2}}, \quad \lambda=\frac{\eta}{1-\delta^{2}}, \quad \xi_{-i m}=\frac{\delta \epsilon_{i m}+\epsilon_{-i m}}{1-\delta^{2}}
$$

The $\xi_{-i m}$ expression in (16) shows that $\ln F R E Q_{-i m}$ is correlated with $\epsilon_{i m}$, leading to simultaneity bias in the OLS estimates of (14), as discussed above. Assuming $|\delta|<1$, which is required for stability of the Cournot-Nash equilibrium, this correlation is positive (negative), with the direction of bias upward (downward), as the reaction function slope $\delta$ is positive (negative). The OLS slope estimate is thus biased away from zero. In addition, if $\epsilon_{i m}$ and $\epsilon_{-i m}$ are positively correlated, as is likely given that unobserved route characteristics will be elements of both error terms, then (16) shows there is an additional source of (positive) correlation

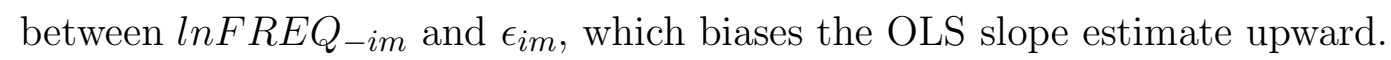

The first-stage regression in (15) relates the competitor's frequency to route characteristics $X_{m}$, to its own identity, as captured by $D_{-i m}$ (the vector of instruments), and to the identity 
of the other airline on the route, carrier $i$, as captured by $D_{i m}$. Note that, in the legacylegacy duopoly case, the first-stage regression is estimated using each of the two observations per route, with the values of the two carrier dummies switching between observations. Fitted values for the frequencies on the right-hand side of (14) are then generated for both carriers on a route, with the values differing because the estimates of the coefficient vectors $\rho$ and $\lambda$ will be different.

In addition to $D_{i m}$, another carrier-characteristics variable, denoted $H_{i m}$, measures the hub status of the route endpoints for carrier $i$. This variable equals the geometric mean of number of destinations served by the carrier from the route endpoints. A large value for this variable, which indicates that one or both of the endpoints is a hub for the carrier, should lead to high frequency on the route as the airline seeks to accommodate both passengers connecting at the hub and passengers terminating their trips at the hub endpoint.

The same hub-status variable is also computed for the other carrier on the duopoly route, and it might initially appear that it could serve as an instrument along with the competitor dummies. However, overidentification tests usually show that competitor hub status is not a valid instrument. In other words, the tests show that it is illegitimate to exclude this hubstatus variable from the right-hand side of the own-carrier reaction function. The implication is that the position of the reaction function depends on endpoint hub status for both the given carrier and its competitor. This conclusion is, in some sense, natural given that the division of traffic on a route will be skewed in favor of the airline that operates a hub at one endpoint. Failure to capture this traffic-division effect by excluding the other carrier's hubstatus variable (measuring only own-carrier hub status) will give a false picture of the height of the own-carrier reaction function. With the hub-status variables for both carriers appearing the reaction function, the variable $Z_{i m}$ then includes a vector $E_{i m} \equiv\left\{H_{i m}, H_{-i m}\right\}$ along with $D_{i m}$. Although it was initially suppressed to simplify the discussion, the $E_{i m}$ vector then appears as covariate in the first-stage regression (15), as does $E_{-i m}$, which shifts carrier $i$ 's reaction function along with $D_{-i m}$. But since $E_{-i m}$ and $E_{i m}$ just involve different orderings of $H_{i m}$ and $H_{-i m}$, the implication is that these two latter variables appear in the first stage.

In addition to estimating the legacy-legacy reaction function, reaction functions involving 
low-cost carriers (LCCs) are also estimated. In an analogy to the legacy-legacy case, a reaction function is estimated for LCC-LCC duopoly routes, where two LCCs alone compete with one another. But in addition to studying frequency competition between carriers of the same type, asymmetric competition is also considered, with reaction functions estimated for duopoly routes where a legacy carrier competes with an LCC. In this case, the reaction functions are allowed to differ by the type of carrier, with an LCC's response to an increase in frequency by a legacy competitor allowed to differ from a legacy carrier's response to an increase in LCC frequency. Note that in estimating the LCC-legacy reaction function, the second-stage regression only uses the LCC observations for the sample routes. Correspondingly, the legacy-LCC reaction function is estimated using only the legacy observations in the second stage. Observations for the other carrier type are used in the first-stage regressions, with a separate regression run for each case.

Finally, a pooled model is estimated, where all three types of duopoly routes are intermixed without distinguishing between carrier types. This model, which serves as a kind of benchmark, assumes that carriers react in the same way to all competitors, independently of their own type (legacy or LCC) or the type of the competitor. This assumption may be incorrect, and if so, the validity of instruments is compromised. For the dummies to be valid instruments, they should be uncorrelated with the unobserved determinants of own-carrier frequency, as noted above. But with the carrier types mixed, the dummies indicate, for example, whether a legacy carrier faces an LCC competitor rather than another legacy competitor on a route. The position of the actual reaction function, however, might depend on the competitor's type, with a legacy carrier, for example, perhaps offering more flights when competing with an LCC. But with the reaction function's intercept constrained to be equal across cases, the effect of the competitor's LCC status would then be captured in the error term. The upshot is that the other-carrier dummies would be correlated with the reaction function's error term, leading to biased estimates.

By contrast, when routes are divided according to the types of competing carriers, this problem would appear not to be present. In the legacy-legacy case, for example, there is little reason to expect that the particular identity of the competing legacy carrier would be corre- 
lated with the unobserved determinants of own-frequency. Similarly, conditional on an LCC's competitor being a legacy carrier, there is little reason to expect that the legacy's particular identity matters. While the same arguments may be valid in the LCC-LCC and legacy-LCC cases, it could be argued that Southwest, the largest LCC carrier, may play a different role than other LCCs. However, distinguishing among LCCs turns out to be impractical. ${ }^{10}$

\subsection{Data}

The data come from the US Department of Transportation's T-100 service-segment database, which contains domestic nonstop flight-frequency data reported by US carriers, with the route endpoints being individual airports. ${ }^{11}$ The data are used to compute quarterly frequency for the second quarter of 2010, a period after the completion of Delta/Northwest merger and prior to the announcement of United/Continental merger. To ensure that flights are regularly scheduled, monthly observations are dropped if the carrier is shown as performing fewer than 20 departures during the month. A carrier with less than 20 departures during each month of the quarter is thus not counted as being present on a route. This restriction is also extended to exclude routes with possible entry or exit during the quarter, a situation that would complicate the measurement of frequency interaction. With entry or exit, some months would have small or zero frequencies for a particular carrier while other months would exceed the 20-departure threshold. Any route with such a frequency pattern for a carrier serving it is excluded. ${ }^{12}$

Following Brueckner, Lee and Singer (2012), legacy carriers are American (AA), Alaska (AS), Continental (CO), Delta (DL), United (UA), US Airways (US) and Hawaiian (HA). LCCs are jetBlue (B6), Frontier (F9), AirTran (FL), Allegiant Air (G4), Spirit (NK), Sun Country (SY), Virgin America (VX) and Southwest (WN). Regional carriers are recoded as their corresponding mainline carriers.

Since a carrier's frequencies tend to be nearly equal in each direction on a route (with some differences due to flight cancellations), the frequency measure is computed in a nondirectional fashion. A carrier's monthly departures are summed over the second quarter of 2010 for each direction on a route, with the average across the two directions then computed. Among the route characteristics, distance in miles between the two airports is reported in the T-100 database. Since longer distances should yield lower frequencies, a negative shift coefficient in 
the reaction function is expected. The income variable is the geometric mean of the highincome shares of the two endpoint populations, with the share for an endpoint equal to the proportion of households in the MSA containing the airport with annual incomes greater than $\$ 75,000$ (gathered from the 2010 State and Metropolitan Databook). The population measure is the geometric mean of the endpoint MSA populations from the 2010 US Census of Population and Housing Occupancy Status. Higher incomes and populations are expected to shift the reaction function upward. Following Pai (2010), the leisure-route variable takes on the value one when either endpoint is Las Vegas (LAS) or Orlando (MCO) and zero otherwise, and its coefficient is expected to be positive. The endpoint hub-status variable is computed for the first quarter of 2010 to avoid endogeneity. This variable, which equals the geometric mean of the number of destinations served from the route endpoints by the carrier (including international destinations), is computed using the T-100 database, and a positive coefficient for the own-carrier variable and a negative coefficient for that of the competitor are expected.

Summary statistics for the data are presented in Tables 1-3. Table 1 shows the number of duopoly routes broken down by carrier mix, while also showing flight frequencies by carrier type. Note that legacy carriers offer higher frequencies on average than LCCs. Table 2 presents variable means and other statistics, while Table 3 shows airline presences on duopoly routes by tabulating the percentage of these routes on which a given carrier is present.

\section{Main Empirical Results}

This section present the main results. Several diagnostic tests are carried out for each model, including the Durbin-Wu-Hausman exogeneity test and the Sargan overidentification test. In addition, to appraise instrument strength, the first-stage F statistic for the instruments is computed and compared to rule-of-thumb value of 10 .

\subsection{Results for the pooled duopoly case}

To start, the pooled duopoly model, where LCCs and legacy carriers are not distinguished, is analyzed. The sample consists of 371 routes, with two carrier observations per route. Table 4 presents results for the pooled duopoly regression, with columns (1) and (3) showing the estimated coefficients for the OLS and 2SLS regressions, respectively. The OLS results 
are presented for comparison, and the regressions use clustered robust standard errors, with clustering by route. Such clustering is needed because omitted route-specific variables affect frequencies for both duopoly carriers, leading to error correlation within each route.

The central result in Table 4 is the estimate of the reaction function's slope, given by the coefficient of the competitor's frequency variable. Under the log specification, the slope shows the percentage in change in carrier $i$ 's frequency in response to a 1 percent increase in $-i$ 's frequency. While the estimated OLS slope coefficient is positive and significantly different from zero, the 2SLS estimate is only one-third as large and statistically insignificant, a finding that appears to suggest the absence of strategic frequency interaction. However, the diagnostic tests on the instruments indicate that this conclusion may be unwarranted, as follows. The Durbin-Wu-Hausman test rejects exogeneity of the competitor's frequency at the 10 percent level (see the footnote to Table 4). In addition, the first-stage regression, shown in the first column of Table 5, yields an F statistic of 19.28 for the instruments, suggesting that they are not weak. But the Sargan overidentification test soundly rejects validity of the instruments, with a $\mathrm{p}$ value below 1 percent (see the footnote to Table 4). The test thus suggests that the second-stage error term is correlated with the competing-carrier dummies, a possibility that was recognized in the previous discussion.

This finding points to a need to distinguish between carrier types in attempting to estimate reaction functions. However, before turning to this task, it is useful to consider the estimated coefficients of the remaining variables in Table 4, even though these coefficients could be biased given the failure to properly correct for endogeneity of the competitor's frequency. As expected, an increase in endpoint populations and incomes shifts the reaction function up, while an increase in distance shifts it down. The reaction function is higher on a leisure route, and it shifts upward when the carrier serves more destinations from the route endpoints, shifting down when the competitor serves more such destinations.

The carrier dummy coefficients indicate, in percentage terms, frequency differences across carriers relative to American (the omitted carrier). For example, the US coefficient of 0.20 indicates that US Airways offers frequencies about 20 percent higher than American, holding the competitor's frequency and route characteristics constant. 
Even though the results in Table 4 are not reliable, an understanding of the setup of firststage regressions is needed for the subsequent analysis. Looking more closely at column (1) of Table 5, the IV prefix on the second set of carrier dummies indicates that they belong to the competing carrier. Recall that the first-stage regression gives the Cournot-Nash equilibrium solution for carrier $-i$ 's frequency, which corresponds to the intersection of reaction functions. Since both reaction functions appear to shift out for a shorter route, one with larger populations or high-income shares, or for a leisure route, equilibrium frequencies both rise, as seen in the estimated coefficients. The competitor hub-status coefficient indicates that a larger number of competitor destinations served from the endpoints leads to higher competitor frequency. The coefficients of the own hub-status variable, expected to be negative, is positive but insignificant.

Predicted frequencies on a duopoly route served by, say, UA and DL are found as follows. To find UA's predicted frequency, the IVUA dummy is set equal to 1 along with the DL dummy, and the competitor hub-status variables are set at UA's values while the own hub-status variables take DL's values. DL's predicted frequency is found by the reverse substitutions.

\subsection{Results for the legacy-legacy duopoly case}

The unsatisfactory results for the pooled regression show the need to distinguish between carrier types, and this section accordingly restricts the sample to the 166 duopoly routes served by two legacy carriers, yielding 332 observations. Table 6 shows the OLS and 2SLS results. The 2SLS slope coefficient is now statistically significant and positive, and it is considerably larger in magnitude than the OLS coefficient, which is also significant, an outcome that is discussed further below. The 2SLS estimate suggests that a carrier raises its own frequency by about 0.7 percent in response to a 1 percent increase in the competitor's frequency. This finding indicates that frequencies are strategic complements rather than substitutes, in contrast to the prediction of the theoretical model. Recall, however, that a different model structure could yield a positive slope like the one in Table 6. Moreover, the slope coefficient shows that strategic interaction is very strong, with a carrier responding in almost one-for-one fashion to an increase in its competitor's flight frequency.

To judge whether the resulting evidence of strategic interaction is credible, the diagnostic tests on the instruments must be checked. Exogeneity of the competitor's frequency is rejected 
at the 5 percent level, and the $\mathrm{F}$ statistic for the instruments is slightly above the rule-ofthumb value of 10, suggesting that they are not weak (see the second column of Table 5). In addition, the overidentification test indicates that the instruments are valid, with a $\mathrm{p}$ value of 0.51 . Therefore, all of the diagnostic tests are favorable, indicating that the existence of strategic frequency interaction among legacy carriers is a valid inference from the results.

Although distance, income, and the endpoint hub-status variables shift the reaction function as before, the population and leisure-route coefficients, though positive, are insignificant (the income coefficient is also only marginally significant). Despite the relatively large F statistic, only the Continental carrier dummy coefficient is individually significant, showing that CO frequencies are about 20 percent greater than American's, other things equal.

As a robustness check for the legacy-legacy case, Table 7 shows the results for a linear, rather than log-linear, regression. In addition to this functional-form change, the population, income, and hub-status variables are now all computed using simple means of the endpoint values rather than geometric means. The first-stage regression is shown in the first column of Table 8. Although the F statistic for the instruments falls to 8.26, slightly below the rule-ofthumb value, the overidentification test continues to show validity of the instruments. ${ }^{13}$ The reaction-function slope coefficient remains significantly positive, and in addition, coefficients for all of the shift variables are now significant. These findings show that the evidence of strategic interaction is reasonably robust to changes in the form of the regression.

\subsection{Results for the LCC-LCC duopoly case}

This section restricts the sample to the 35 duopoly routes served by two LCCs, yielding 70 observations. Table 9 shows the OLS and 2SLS results for the log-linear specification. Although the reaction-function slope coefficient is insignificant in the OLS case, the 2SLS slope is significantly positive. Its magnitude of 0.76 is close to that in the legacy-legacy case, indicating that the strength of strategic interaction is similar within the two carrier types, being strong in both cases.

The diagnostic tests on the instruments are again fully satisfactory, as in the log-linear legacy-legacy case. Exogeneity of the competitor's frequency is soundly rejected, the value of the F statistic for the instruments is almost 18 (see Table 5), and the overidentification test 
fails to reject validity of the instruments (with a p-value of 0.72 ). Therefore, as in Table 7 , the evidence of strategic frequency interaction is credible.

Among the shift variables, the population, income, and leisure-route coefficients are insignificant, while the remaining coefficients are significant with the expected signs. With LCCs more oriented to nonbusiness passengers than legacies, the failure of the high-income shares to shift the reaction function may be plausible (recall that this variable's coefficient was marginally significant in the legacy-legacy case). Also, with LCCs tending to serve leisure passengers on all routes (leisure or otherwise), the insignificance of the leisure-route coefficient may make sense. The only LCC with frequencies significantly different from those of jetBlue, the omitted LCC carrier, is Virgin America, whose frequencies appear to be more than twice as high. ${ }^{14}$

As a robustness check, Table 10 presents the LCC-LCC results for the alternative specification, with the second column of Table 8 showing the first-stage regression. The 2SLS slope coefficient is again positive and significant, suggesting the presence of strategic interaction. Although the F statistic for the instruments falls to 7.77 , the overidentification test continues to show their validity, with a $\mathrm{p}$ value of $0.89 .^{15}$ Among the shift variables that had insignificant coefficients under the log-linear specification, population now has a significantly positive effect on frequencies.

\subsection{Results for the legacy-LCC and LCC-legacy duopoly cases}

With the previous results showing the presence of strategic frequency interaction within carrier types, the next step is to investigate interaction across types. Unfortunately, however, this investigation turns out to be unsuccessful. The reason is that, for both the legacy-LCC and LCC-legacy cases, the performance of the competing-carrier dummies as instruments is unsatisfactory. On the 170 duopoly routes where the carrier types are mixed, the competingcarrier dummies have little influence over the frequencies chosen by the competitor. Evidently, when paired with a carrier of the other type, a competing carrier's identity appears not to matter in determining its own frequencies. In other words, when it comes to frequencies, all legacies behave the same way when their competitor is an LCC, and vice versa, a pattern that has no obvious explanation. 
This outcome, which holds in both the legacy-LCC and LCC-legacy cases, can be illustrated by considering the latter case. ${ }^{16}$ Table 11 presents the OLS and 2SLS results for the the LCClegacy case, showing the LCC reaction function when a legacy carrier is the competitor (the log-linear specification is used). The 2SLS slope coefficient is not significantly different from zero, which might be viewed as evidence that LCC carriers do not consider legacy choices in setting their own frequencies, a plausible possibility. However, the last column of Table 5 shows a very low F statistic of 0.97 for the instruments, none of whose coefficients are individually significant at the 5 percent level. Even though the overidentification test cannot reject validity of the instruments, the tiny F statistic means that the 2SLS results are not reliable. Therefore, the absence of strategic LCC interaction with a legacy competitor, although a tantalizing conclusion, is not credible. The legacy-LCC regression (not shown) also yields an insignificant 2SLS slope, but it suffers from the very same instrument deficiencies. The upshot is that the present data cannot generate a reliable measure of strategic interaction across carrier types.

The same obstacle arises for a sample of 87 oligopoly routes. Focusing on 3-carrier routes, and estimating reaction functions for a pooled model as well as for the 1-legacy/2-LCC and 1-LCC/2-legacy cases, the performance of the carrier-dummy instruments is unsatisfactory in each case (results are not shown). ${ }^{17}$ The first-stage regressions yield unacceptably low $\mathrm{F}$ statistics, again indicating that flight frequencies do not vary significantly across carriers on such routes.

\subsection{Overall lessons}

The challenge in estimating reaction functions is to find instruments that help determine the level of the endogenous right-hand variable, in this case the competitor's flight frequency. Good choices for instruments are variables that shift the competitor's reaction function without being correlated with the unobservable determinants of the carrier's own frequency. Variables that, in principle, meet this requirement are measures of the competing carrier's characteristics. One such characteristics variable, which is actually both carrier- and route-dependent, is the endpoint hub-status measure, but it turns out to be invalid as an instrument since it directly determines own-frequency, as discussed above. A remaining choice is the vector of dummy variables indicating carrier identities. As long as these variables shift the flight-frequency 
reaction function, with carrier identities mattering in the choice of frequencies, these variables should perform successfully as instruments.

As the preceding discussion shows, the dummy variables meet this requirement for some types of routes but not others. On duopoly routes where the carriers are of same type (both legacies or both LCCs), carrier identities matter in the determination of frequencies. But on mixed duopoly and oligopoly routes, as well in the pooled oligopoly case, carrier identities do not exert enough influence on frequencies to be viable as instruments. Given this failure, one might wonder whether objective carrier-characteristics measures might do a better job. However, regressions using several such variables, including cost per seat mile and several measures of fleet size relative to network size (presumably a determinant of frequencies), did not yield better results for the problematic mixed-route cases. This outcome is no surprise, of course, since carrier dummies offer the most comprehensive way of capturing differences in carrier characteristics.

Another approach, which follows Berry et al. (1995), is to choose an instrument related to the other "products" offered by a carrier. The chosen instrument is the weighted average of the competitor's (logged) flight frequencies on the other routes it operates that do not share endpoints with the given route, with larger weights used on routes that have endpoint populations similar to those on the given route. This instrument, however, performs poorly by itself, and including it along with the carrier dummies does not improve the results.

With no other attractive instruments apparently available, the present results may offer the best that can be done in investigating strategic interaction in the choice of flight frequencies. Fortunately, it appears that the strength of interaction can be measured with some confidence for at least some types of routes.

One final note of caution regarding the results concerns the direction of bias in the OLS estimates of the reaction-function slopes. While the discussion in section 3 indicated that the OLS slope should be biased away from zero, the legacy-legacy and LCC-LCC estimates yield the opposite pattern, with the positive 2SLS slope estimates being larger, not smaller, than the OLS estimates. This outcome might suggest that the instruments, despite passing the various diagnostic tests, are somehow invalid. More fundamentally, the finding instead might indicate 
that the Cournot-Nash depiction of the choice of flight frequencies is inappropriate, with some other behavioral model being relevant instead. Or, recognizing that the slope estimates are random variables, the finding may just reflect statistical noise.

\section{Multimarket Contact}

Evans and Kessides' (1994) work on multimarket contact added an important innovation to reduced-form models of airline pricing by showing that extensive contact between competitors on other routes could soften price competition on a given route, with carriers fearing retaliation elsewhere when they cut fares. Evans and Kessides showed that airlines with high multimarket contact practice "mutual forbearance" by charging higher fares on routes they jointly serve.

With the view of airline competition broadened to include both fares and frequencies, a natural question is whether mutual forebearance exists in both the quality and price dimensions. In other words, do airlines with high multimarket compete less vigorously in frequencies on routes where they are both present? While this question could be addressed in a reduced-form fashion, it also can be addressed in the current, reaction-function context. The question then is whether multimarket contact shifts the reaction function downward, with carriers offering lower frequencies on routes where multimarket contact with the competitor is high.

To address this question, a contact variable is constructed following Evans and Kessides (1994), and the variable is then added to the previous legacy-legacy and LCC-LCC duopoly regressions. For a duopoly route, the contact measure is simply the total number of routes on which the two carriers are both present. Table 12 shows the matrix containing these route counts for all pairs of carriers.

Table 13 presents the results. To simplify the table, the dummy variables are omitted and only 2SLS estimates are displayed. With the coefficient of the contact measure insignificant in both regressions, the results suggest that multimarket contact does not shift the reaction functions in the legacy-legacy and LCC-LCC cases, a finding that contradicts the mutual forbearance hypothesis. ${ }^{18}$ A possible explanation is that, with frequencies a less-prominent competitive tool than fares, airlines need not adjust their competitive behavior in the frequency dimension in response to high multimarket contact, letting mutual forebearance in prices do 
all the work.

In the present context, the reduced-form results of Evans and Kessides (1994) correspond the estimates of the first-stage regression. These results, which are not shown, provide a somewhat different picture. Although the coefficient of the contact variable is insignificant in the LCC-LCC first-stage regression, the legacy-legacy first stage shows a significant and positive coefficient, indicating that multimarket contact raises equilibrium frequencies. This outcome is a consequence of the positive reaction-function coefficient for contact, which indicates that both functions shift outward (although not in a statistically significant fashion) as multimarket contact increases, raising equilibrium frequencies. This conclusion is, of course, the opposite of what mutual forebearance would predict and is thus counterintuitive. Moreover, the failure of the contact effect to appear significantly in the reaction functions themselves casts some doubt on the conclusion. The lesson to be drawn is that the results definitely do not show evidence of mutual forebearance in frequency choices, with the effect of multimarket contact possibly running in the opposite direction for legacies, although not for LCCs.

\section{Using the Estimates}

The estimated reaction functions can be used to predict the effects on flight frequencies of changes in the airline operating environment, which may shift the positions of the functions for one or more carriers. Consider, for example, the impact of a change in an individual airline's "scope clause." A scope clause is now typically part of the collective bargaining agreement between a legacy carrier and its pilot's union, with the clause limiting the extent to which the airline's service can be operated by regional carriers. The goal is to limit the reliance on regional-carrier pilots in providing service under the airline's brand name, preserving jobs for the pilots who fly the mainline fleet. A scope clause often limits the number of regional aircraft that can be operated as well as their seat capacities, with both limitations serving to cap the number of non-mainline seats that the carrier can use in providing its service. Relaxation of a scope clause thus allows greater reliance on small planes, either by allowing a larger number to be used or by allowing the operation of larger regional aircraft (which remain smaller than mainline planes) in the provision of service. The mainline carrier therefore gains flexibility in 
matching aircraft to market conditions.

Scope clauses are relevant to the present analysis because, by limiting the use of small planes, they may constrain a carrier's ability to provide high flight frequencies. For example, carriers might be prevented from raising frequencies on high-volume routes by adding a few regional-jet flights each day to supplement mainline operations, a change that would require raising the share of such jets in the combined fleet. From the perspective of the current framework, the key observation is that relaxation of a carrier's scope clause may lead to an upward shift in its reaction function, with a higher frequency provided for any given level of the competitor's frequency. Concretely, this change would be reflected in an increase in the coefficient of the dummy variable identifying that carrier. The larger dummy coefficient, in effect, raises the carrier-specific intercept of the reaction function.

How will a relaxation of one carrier's scope clause affect flight frequencies? Consider the case of American Airlines (AA), which has recently negotiated a relaxation of its scope clause under bankruptcy proceedings, and consider a route where AA competes with another legacy carrier (call it YZ). The upward shift in AA's reaction function, which is shown in Figure 1, will lead to a new Cournot-Nash equilibrium with higher frequencies for both American and carrier YZ. In addition, the figure shows that AA's frequency will rise by more than YZ's in moving to the new equilibrium. Analytically, let $\delta$ denote the reaction function's slope (as in (14)) and let $\eta_{A A}$ denote AA's dummy coefficient (represented by the intercept $\alpha$ in (14) since $\mathrm{AA}$ is the omitted carrier). Then, letting $\eta_{A A}$ change by $\Delta \eta_{A A}$ and using $f$ 's to denote frequencies (as in the theoretical model), the changes in frequencies on the route, $\Delta f_{A A}$ and $\Delta f_{Y Z}$, must satisfy

$$
\begin{aligned}
\Delta f_{A A} & =\Delta \eta_{A A}+\delta \Delta f_{Y Z} \\
\Delta f_{Y Z} & =\delta \Delta f_{A A},
\end{aligned}
$$

where (17) and (18) come from AA's and YZ's reaction functions. Solving yields

$$
\Delta f_{A A}=\frac{\Delta \eta_{A A}}{1-\delta^{2}}, \quad \Delta f_{Y Z}=\frac{\delta \Delta \eta_{A A}}{1-\delta^{2}}
$$


Using the $\delta$ value of 0.625 from the linear specification in Table $7,(19)$ shows that $\Delta f_{A A}=$ $1.641 \Delta \eta_{A A}$ and $\Delta f_{Y Z}=1.026 \Delta \eta_{A A}$. Therefore, $f_{A A}$ increases by almost twice the increase in the AA intercept, while the increase in $f_{Y Z}$ about matches the intercept's increase. The ratio of the two changes is $1.641 / 1.026=1.600=1 / \delta$. The lesson is that a relaxation of an legacy airline's scope clause (reflected, by assumption, in a larger dummy coefficient) raises equilibrium frequencies on all the duopoly routes where it competes with another legacy carrier, but that its own frequency rises by sixty percent more than that of its competitor. Although it is not possible to quantify the connection between AA's scope clause and the magnitude of $\eta_{A A}$ or to validate the assumption that the clause only affects the intercept, these calculations show how the estimates from the model might be used to generate qualitative insights.

A final point is that the first-stage estimates, which correspond to the reduced-form of the structural model, could be used instead to generate analogous conclusions. However, because the first-stage estimates are derived statistically, not through algebraic manipulation of the reaction-function estimates, the answers from this method may be different. ${ }^{19}$

\section{Conclusion}

This paper has provided empirical evidence on product-quality competition in the airline industry. Focusing on a main element of quality, flight frequency, the paper has estimated reaction functions in a search for strategic interaction in the determination of frequencies. Regressions for duopoly routes where two competitors are of the same type (two LCCs or two legacy carriers) yield credible, significantly positive 2SLS slope estimates. Strategic interaction therefore appears to occur on such homogenous routes, and the slope estimates indicate that it is strong, with a carrier responding in almost one-for-one fashion to an increase in its competitor's frequency (a conclusion that applies on both legacy and LCC routes). But on duopoly routes where the competing carriers are of different types, the weak performance of the instruments, which are needed to identify strategic interaction, prevents a strong conclusion from being reached. Therefore, while the analysis shows the presence of strategic interaction within carrier types, the existence of interaction across types remains an open question. Regressions including a multimarket-contact variable show no evidence of mutual forbearance in frequency 
competition within carrier types.

With little existing empirical work on product-quality competition in the industrial organization literature, this paper points the way toward a possible new line of research. In other industries where substantial quality variation is observed, either cross-sectionally or intemporally, reaction functions could be estimated in an attempt to expose the nature of strategic interaction. 
Table 1: Duopoly Route Structure

\begin{tabular}{lccc}
\hline \hline Route Structure & \multicolumn{2}{c}{ Mean Frequency } & Number of Routes \\
\hline & Legacy & LCC & \\
\hline pooled & 427.55 & 276.28 & 371 \\
legacy-legacy & 402.94 & - & 166 \\
LCC-LCC & - & 232.36 & 35 \\
legacy-LCC & 475.62 & 294.37 & 170 \\
\hline
\end{tabular}

Table 2: Summary Statistics for Duopoly Routes

\begin{tabular}{lcccc}
\hline \hline \multicolumn{1}{c}{ Variable } & Mean & Std.Dev. & Min & Max \\
\hline Frequency & 378.622 & 249.396 & 78 & 1797 \\
Distance & 819.846 & 545.192 & 67 & 2918 \\
Geometric Mean of Income above $\$ 75,000$ & 34.783 & 4.392 & 23.769 & 51.327 \\
Geometric Mean of Population (in hundred thousands) & 30.079 & 15.266 & 5.670 & 95.529 \\
Leisure Route & 0.094 & 0.292 & 0 & 1 \\
Geometric Mean of Number of Destinations & 19.828 & 16.211 & 0 & 169 \\
\hline
\end{tabular}


Table 3: Airline Presences on Duopoly Routes

\begin{tabular}{lcc}
\hline \hline Airline Code & Airline & Share of Routes \\
\hline AA & American & $14.15 \%$ \\
AS & Alaska & $3.50 \%$ \\
CO & Continental & $6.87 \%$ \\
DL & Delta & $16.44 \%$ \\
UA & United & $15.09 \%$ \\
US & US Airways & $11.05 \%$ \\
HA & Hawaiian & $0.27 \%$ \\
\hline B6 & JetBlue & $4.72 \%$ \\
F9 & Frontier & $2.43 \%$ \\
FL & AirTran & $9.03 \%$ \\
G4 & Allegiant Air & $0.13 \%$ \\
NK & Spirit & $1.21 \%$ \\
SY & Sun Country & $0.13 \%$ \\
VX & Virgin America & $0.27 \%$ \\
WN & Southwest & $14.42 \%$ \\
\hline \hline
\end{tabular}


Table 4: Pooled Regression for Duopoly Routes

\begin{tabular}{|c|c|c|c|c|}
\hline & OLS & & 2SLS & \\
\hline & (1) & $(2)$ & (3) & (4) \\
\hline Variables & Coeff. & Std.Err. & Coeff. & Std.Err. \\
\hline Log Competitor Frequency & $0.301^{* *}$ & $(0.058)$ & 0.129 & $(0.103)$ \\
\hline Distance & $-0.0004^{* *}$ & $(0.0001)$ & $-0.001 * *$ & $(0.0001)$ \\
\hline Geometric Mean of Income above $\$ 75,000$ & $0.017^{* *}$ & $(0.004)$ & $0.022^{* *}$ & $(0.005)$ \\
\hline Geometric Mean of Population & $0.005^{* *}$ & $(0.002)$ & $0.007^{* *}$ & $(0.002)$ \\
\hline Leisure Route & $0.167^{* *}$ & $(0.054)$ & $0.178^{* *}$ & $(0.065)$ \\
\hline Geometric Mean of Own \# Destination & $0.017^{* *}$ & $(0.002)$ & $0.017^{* *}$ & $(0.002)$ \\
\hline Geometric Mean of Competitor's \# Destination & $-0.004^{*}$ & $(0.002)$ & -0.001 & $(0.002)$ \\
\hline AS & 0.110 & $(0.115)$ & 0.114 & $(0.111)$ \\
\hline B6 & $-0.285^{* *}$ & $(0.110)$ & $-0.325^{* *}$ & $(0.106)$ \\
\hline $\mathrm{CO}$ & $0.260^{* *}$ & $(0.082)$ & $0.248^{* *}$ & $(0.079)$ \\
\hline DL & 0.031 & $(0.065)$ & 0.011 & $(0.062)$ \\
\hline F9 & -0.059 & $(0.103)$ & -0.061 & $(0.094)$ \\
\hline FL & $-0.254^{* *}$ & $(0.072)$ & $-0.234^{* *}$ & $(0.076)$ \\
\hline G4 & $-0.713^{* *}$ & $(0.097)$ & $-0.863^{* *}$ & $(0.125)$ \\
\hline HA & 0.111 & $(0.096)$ & 0.163 & $(0.102)$ \\
\hline NK & -0.200 & $(0.110)$ & -0.182 & $(0.105)$ \\
\hline SY & $-0.620^{* *}$ & $(0.093)$ & $-0.535^{* *}$ & $(0.107)$ \\
\hline UA & 0.051 & $(0.065)$ & 0.042 & $(0.061)$ \\
\hline US & $0.212^{* *}$ & $(0.066)$ & $0.199 * *$ & $(0.065)$ \\
\hline vX & $0.562^{* *}$ & $(0.151)$ & $0.557^{* *}$ & $(0.136)$ \\
\hline WN & $-0.214^{* *}$ & $(0.068)$ & $-0.208^{* *}$ & $(0.067)$ \\
\hline Constant & $3.321^{* *}$ & $(0.305)$ & $4.112^{* *}$ & $(0.504)$ \\
\hline Observations & 742 & & 742 & \\
\hline$R^{2}$ & 0.528 & & - & \\
\hline
\end{tabular}

$1 * * \mathrm{p}<0.01, * \mathrm{p}<0.05$.

${ }^{2}$ Standard errors are clustered robust, clustering by route.

${ }^{3}$ Dependent variable: Log Own Frequency.

${ }^{4}$ test of exogeneity: $\mathrm{p}=0.076$

${ }^{5}$ test of overidentifying restrictions: Sargan chi-squared $(13)=34.101(\mathrm{p}=0.001)$ 
Table 5: First-stage Regressions for Duopoly Routes

\begin{tabular}{|c|c|c|c|c|}
\hline & Pooled & Legacy-Legacy & LCC-LCC & LCC-Legacy \\
\hline & (1) & $(2)$ & (3) & (4) \\
\hline Variables & Coeff. & Coeff. & Coeff. & Coeff. \\
\hline Distance & $\begin{array}{c}-0.001 * * \\
(0.0001)\end{array}$ & $\begin{array}{c}-0.001 * * \\
(0.0001)\end{array}$ & $\begin{array}{c}-0.001 * * \\
(0.0001)\end{array}$ & $\begin{array}{c}-0.001 * * \\
(0.0001)\end{array}$ \\
\hline Geometric Mean of Income above $\$ 75,000$ & $\begin{array}{c}0.025^{* *} \\
(0.006)\end{array}$ & $\begin{array}{c}0.025^{* *} \\
(0.008)\end{array}$ & $\begin{array}{c}0.012 \\
(0.027)\end{array}$ & $\begin{array}{l}0.018^{*} \\
(0.009)\end{array}$ \\
\hline Geometric Mean of Population & $\begin{array}{c}0.008^{* *} \\
(0.002)\end{array}$ & $\begin{array}{c}0.004 \\
(0.003)\end{array}$ & $\begin{array}{c}0.021^{* *} \\
(0.005)\end{array}$ & $\begin{array}{c}0.004 \\
(0.002)\end{array}$ \\
\hline Leisure Route & $\begin{array}{l}0.168^{*} \\
(0.083)\end{array}$ & $\begin{array}{c}0.114 \\
(0.184)\end{array}$ & $\begin{array}{l}-0.050 \\
(0.123)\end{array}$ & $\begin{array}{c}0.424^{* *} \\
(0.129)\end{array}$ \\
\hline Geometric Mean of Own \# Dest. & $\begin{array}{c}0.002 \\
(0.001)\end{array}$ & $\begin{array}{c}0.001 \\
(0.002)\end{array}$ & $\begin{array}{c}0.014 \\
(0.009)\end{array}$ & $\begin{array}{c}0.001 \\
(0.004)\end{array}$ \\
\hline Geometric Mean of Competitor's \# Dest. & $\begin{array}{c}0.016^{* *} \\
(0.002)\end{array}$ & $\begin{array}{c}0.019 * * \\
(0.003)\end{array}$ & $\begin{array}{c}0.040^{* *} \\
(0.008)\end{array}$ & $\begin{array}{c}0.010^{* *} \\
(0.003)\end{array}$ \\
\hline AS & $\begin{array}{c}0.187 \\
(0.113)\end{array}$ & $\begin{array}{c}0.115 \\
(0.151)\end{array}$ & NA & NA \\
\hline $\mathrm{CO}$ & $\begin{array}{c}0.020 \\
(0.104)\end{array}$ & $\begin{array}{c}0.002 \\
(0.119)\end{array}$ & NA & NA \\
\hline DL & $\begin{array}{l}-0.008 \\
(0.071)\end{array}$ & $\begin{array}{c}-0.419^{* *} \\
(0.096)\end{array}$ & NA & NA \\
\hline UA & $\begin{array}{c}0.007 \\
(0.118)\end{array}$ & $\begin{array}{l}-0.131 \\
(0.131)\end{array}$ & NA & NA \\
\hline US & $\begin{array}{c}0.102 \\
(0.090)\end{array}$ & $\begin{array}{c}0.109 \\
(0.107)\end{array}$ & NA & NA \\
\hline HA & $\begin{array}{c}0.344 \\
(0.239)\end{array}$ & $\begin{array}{c}0.041 \\
(0.174)\end{array}$ & NA & NA \\
\hline B6 & $\begin{array}{l}-0.195 \\
(0.108)\end{array}$ & NA & Omitted & Omitted \\
\hline F9 & $\begin{array}{c}0.074 \\
(0.152)\end{array}$ & NA & $\begin{array}{c}0.453 \\
(0.250)\end{array}$ & $\begin{array}{c}0.086 \\
(0.213)\end{array}$ \\
\hline FL & $\begin{array}{c}0.301 * * \\
(0.100)\end{array}$ & NA & $\begin{array}{c}0.421 \\
(0.219)\end{array}$ & $\begin{array}{c}0.526^{* *} \\
(0.163)\end{array}$ \\
\hline G4 & $\begin{array}{c}-0.744^{* *} \\
(0.123)\end{array}$ & NA & $\begin{array}{c}0.121 \\
(0.206)\end{array}$ & NA \\
\hline NK & $\begin{array}{c}0.232 \\
(0.200)\end{array}$ & NA & $\begin{array}{l}0.796^{*} \\
(0.351)\end{array}$ & $\begin{array}{c}0.149 \\
(0.226)\end{array}$ \\
\hline SY & $\begin{array}{c}0.555^{* *} \\
(0.130)\end{array}$ & NA & NA & $\begin{array}{c}0.348 \\
(0.196)\end{array}$ \\
\hline VX & $\begin{array}{c}0.329 * * \\
(0.123)\end{array}$ & NA & $\begin{array}{c}1.039 * * \\
(0.234)\end{array}$ & $\begin{array}{c}1.075^{* *} \\
(0.224)\end{array}$ \\
\hline $\mathrm{WN}$ & $\begin{array}{c}0.033 \\
(0.072)\end{array}$ & NA & $\begin{array}{c}-0.00003 \\
(0.197)\end{array}$ & $\begin{array}{c}0.232 \\
(0.130)\end{array}$ \\
\hline Constant & $\begin{array}{c}4.709 * * \\
(0.206)\end{array}$ & $\begin{array}{c}4.896 * * \\
(0.255)\end{array}$ & $\begin{array}{c}3.859 * * \\
(0.884)\end{array}$ & $\begin{array}{c}4.858^{* *} \\
(0.369)\end{array}$ \\
\hline
\end{tabular}

Continued on next page. 
Table 5: Continued from previous page

\begin{tabular}{|c|c|c|c|c|}
\hline & Pooled & Legacy-Legacy & LCC-LCC & LCC-Legacy \\
\hline & (1) & (2) & (3) & (4) \\
\hline Variables & Coeff. & Coeff. & Coeff. & Coeff. \\
\hline IVAS & $\begin{array}{c}0.140 \\
(0.132)\end{array}$ & $\begin{array}{l}-0.017 \\
(0.195)\end{array}$ & NA & $\begin{array}{c}0.264 \\
(0.208)\end{array}$ \\
\hline IVCO & $\begin{array}{l}0.257^{*} \\
(0.116)\end{array}$ & $\begin{array}{c}0.211 \\
(0.135)\end{array}$ & NA & $\begin{array}{c}0.455 \\
(0.272)\end{array}$ \\
\hline IVDL & $\begin{array}{l}-0.075 \\
(0.085)\end{array}$ & $\begin{array}{c}-0.464^{* *} \\
(0.092)\end{array}$ & NA & $\begin{array}{c}0.334 \\
(0.188)\end{array}$ \\
\hline IVUA & $\begin{array}{c}0.039 \\
(0.119)\end{array}$ & $\begin{array}{l}-0.105 \\
(0.128)\end{array}$ & NA & $\begin{array}{c}0.269 \\
(0.203)\end{array}$ \\
\hline IVUS & $\begin{array}{c}0.194 \\
(0.108)\end{array}$ & $\begin{array}{c}0.234 \\
(0.142)\end{array}$ & NA & $\begin{array}{c}0.334 \\
(0.200)\end{array}$ \\
\hline IVHA & $\begin{array}{c}0.191 \\
(0.144)\end{array}$ & $\begin{array}{l}-0.064 \\
(0.228)\end{array}$ & NA & NA \\
\hline IVB6 & $\begin{array}{c}-0.413^{* *} \\
(0.127)\end{array}$ & NA & Omitted & NA \\
\hline IVF9 & $\begin{array}{l}-0.143 \\
(0.104)\end{array}$ & NA & $\begin{array}{c}0.467 \\
(0.239)\end{array}$ & NA \\
\hline IVFL & $\begin{array}{c}-0.194 \\
(0.120)\end{array}$ & NA & $\begin{array}{c}0.224 \\
(0.169)\end{array}$ & NA \\
\hline IVG4 & $\begin{array}{c}-1.236^{* *} \\
(0.128)\end{array}$ & NA & $\begin{array}{l}-0.047 \\
(0.210)\end{array}$ & NA \\
\hline IVNK & $\begin{array}{l}-0.140 \\
(0.137)\end{array}$ & NA & $\begin{array}{c}0.485^{* *} \\
(0.175)\end{array}$ & NA \\
\hline IVSY & $\begin{array}{c}-0.437^{* *} \\
(0.152)\end{array}$ & NA & NA & NA \\
\hline IVVX & $\begin{array}{c}0.662^{* *} \\
(0.202)\end{array}$ & NA & $\begin{array}{l}1.876^{* *} \\
(0.228)\end{array}$ & NA \\
\hline IVWN & $\begin{array}{c}-0.262^{* *} \\
(0.094)\end{array}$ & NA & $\begin{array}{c}0.052 \\
(0.241)\end{array}$ & NA \\
\hline Observations & 742 & 332 & 70 & 170 \\
\hline$R^{2}$ & 0.500 & 0.436 & 0.711 & 0.590 \\
\hline F-statistic for the IVs & 19.281 & 10.013 & 17.634 & 0.969 \\
\hline
\end{tabular}

$1 * * \mathrm{p}<0.01,{ }^{*} \mathrm{p}<0.05$.

${ }^{2}$ Standard errors are clustered robust, clustering by route.

${ }^{3}$ Dependent variable: Log Competitor Frequency. 
Table 6: Legacy-Legacy Regression

\begin{tabular}{lcccc}
\hline \hline & OLS & \multicolumn{2}{c}{ 2SLS } & \\
\hline \multicolumn{1}{c}{ Variables } & $(\mathbf{1})$ & $\mathbf{( 2 )}$ & $\mathbf{( 3 )}$ & $\mathbf{( 4 )}$ \\
\hline Log Competitor Frequency & Coeff. & Std.Err. & Coeff. & Std.Err. \\
Distance & $0.417^{* *}$ & $(0.078)$ & $0.695^{* *}$ & $(0.110)$ \\
Geometric Mean of Income above $\$ 75,000$ & $-0.0003^{* *}$ & $(0.0001)$ & $-0.0001^{*}$ & $(0.0001)$ \\
Geometric Mean of Population & $0.015^{* *}$ & $(0.005)$ & $0.007^{*}$ & $(0.003)$ \\
Leisure Route & 0.003 & $(0.002)$ & 0.001 & $(0.001)$ \\
Geometric Mean of Own \# Destination & 0.108 & $(0.106)$ & 0.039 & $(0.064)$ \\
Geometric Mean of Competitor's \# Destination & $0.018^{* *}$ & $(0.003)$ & $0.018^{* *}$ & $(0.003)$ \\
AS & $-0.007^{* *}$ & $(0.002)$ & $-0.012^{* *}$ & $(0.003)$ \\
CO & -0.056 & $(0.201)$ & -0.102 & $(0.208)$ \\
DL & $0.221^{*}$ & $(0.092)$ & $0.236^{*}$ & $(0.101)$ \\
UA & $-0.220^{* *}$ & $(0.077)$ & -0.165 & $(0.093)$ \\
US & 0.037 & $(0.072)$ & 0.049 & $(0.079)$ \\
HA & 0.155 & $(0.092)$ & 0.152 & $(0.100)$ \\
Constant & -0.134 & $(0.125)$ & -0.105 & $(0.176)$ \\
Observations & $2.743^{* *}$ & $(0.401)$ & $1.454^{* *}$ & $(0.547)$ \\
$R^{2}$ & 332 & & 332 & \\
\hline \hline
\end{tabular}

$1 * * \mathrm{p}<0.01, * \mathrm{p}<0.05$.

${ }^{2}$ Standard errors are clustered robust, clustering by route.

${ }^{3}$ Dependent variable: Log Own Frequency.

${ }^{4}$ test of exogeneity: $\mathrm{p}=0.015$

${ }^{5}$ test of overidentifying restrictions: Sargan chi-squared $(5)=4.319(\mathrm{p}=0.505)$ 
Table 7: Legacy-Legacy Regression with Linear/Average Specification

\begin{tabular}{|c|c|c|c|c|}
\hline & OLS & & $2 \mathrm{SLS}$ & \\
\hline & (1) & (2) & (3) & $(4)$ \\
\hline Variables & Coeff. & Std.Err. & Coeff. & Std.Err. \\
\hline Competitor Frequency & $0.560^{* *}$ & $(0.063)$ & $0.625^{* *}$ & $(0.112)$ \\
\hline Distance & $-0.067^{* *}$ & $(0.014)$ & $-0.059 * *$ & $(0.020)$ \\
\hline Average Income above $\$ 75,000$ & $6.429^{* *}$ & $(1.634)$ & $5.583^{* *}$ & $(2.016)$ \\
\hline Average Population & $1.646^{* *}$ & $(0.609)$ & $1.426^{*}$ & $(0.657)$ \\
\hline Leisure Route & $82.373^{* *}$ & $(20.615)$ & $72.152^{* *}$ & $(25.612)$ \\
\hline Average of Own \# Destination & $7.197^{* *}$ & $(0.740)$ & $7.310^{* *}$ & $(0.683)$ \\
\hline Average of Competitor's \# Destination & $-4.900 * *$ & $(0.678)$ & $-5.253^{* *}$ & $(0.705)$ \\
\hline AS & 181.901 & $(111.214)$ & 174.426 & $(116.650)$ \\
\hline $\mathrm{CO}$ & -37.199 & $(36.102)$ & -41.028 & $(36.408)$ \\
\hline $\mathrm{DL}$ & -39.594 & $(25.883)$ & -39.295 & $(25.968)$ \\
\hline $\mathrm{UA}$ & $-94.344^{* *}$ & $(29.245)$ & $-97.968^{* *}$ & $(29.294)$ \\
\hline US & 35.426 & $(31.407)$ & 30.927 & $(34.524)$ \\
\hline $\mathrm{HA}$ & $161.253^{*}$ & $(65.726)$ & $153.034^{*}$ & $(71.643)$ \\
\hline Constant & $-168.608^{* *}$ & $(58.905)$ & $-146.194^{*}$ & $(70.237)$ \\
\hline Observations & 332 & & 332 & \\
\hline$R^{2}$ & 0.616 & & - & \\
\hline
\end{tabular}

$1 * * \mathrm{p}<0.01,{ }^{*} \mathrm{p}<0.05$.

${ }^{2}$ Standard errors are clustered robust, clustering by route.

${ }^{3}$ Dependent variable: Own Frequency.

${ }^{4}$ test of exogeneity: $\mathrm{p}=0.555$

${ }^{5}$ test of overidentifying restrictions: Sargan chi-squared $(5)=4.414(\mathrm{p}=0.492)$ 
Table 8: First-stage Regressions with Linear/Average Specification

\begin{tabular}{|c|c|c|}
\hline & Legacy-Legacy & LCC-LCC \\
\hline & (1) & $(2)$ \\
\hline Variables & Coeff. & Coeff. \\
\hline Distance & $\begin{array}{c}-0.160 * * \\
(0.032)\end{array}$ & $\begin{array}{c}-0.225^{* *} \\
(0.039)\end{array}$ \\
\hline Average Income above $\$ 75,000$ & $\begin{array}{c}12.595^{* *} \\
(3.355)\end{array}$ & $\begin{array}{l}-1.066 \\
(8.326)\end{array}$ \\
\hline Average Population & $\begin{array}{c}4.088^{* *} \\
(1.389)\end{array}$ & $\begin{array}{c}4.298^{* *} \\
(1.171)\end{array}$ \\
\hline Leisure Route & $\begin{array}{c}166.853^{* *} \\
(44.347)\end{array}$ & $\begin{array}{l}-23.544 \\
(41.543)\end{array}$ \\
\hline Average of Own \# Dest. & $\begin{array}{c}-1.306^{*} \\
(0.614)\end{array}$ & $\begin{array}{l}-1.010 \\
(4.705)\end{array}$ \\
\hline Average of Competitor's \# Dest. & $\begin{array}{c}6.527^{* *} \\
(0.626)\end{array}$ & $\begin{array}{c}18.697^{* * *} \\
(3.871)\end{array}$ \\
\hline AS & $\begin{array}{c}176.351^{*} \\
(79.994)\end{array}$ & NA \\
\hline $\mathrm{CO}$ & $\begin{array}{c}31.489 \\
(35.231)\end{array}$ & NA \\
\hline DL & $\begin{array}{l}-67.528 \\
(38.266)\end{array}$ & NA \\
\hline UA & $\begin{array}{c}-5.204 \\
(46.588)\end{array}$ & NA \\
\hline US & $\begin{array}{c}83.270 \\
(45.304)\end{array}$ & NA \\
\hline HA & $\begin{array}{c}215.741 \\
(138.096)\end{array}$ & NA \\
\hline B6 & NA & Omitted \\
\hline F9 & NA & $\begin{array}{c}17.637 \\
(73.654)\end{array}$ \\
\hline FL & NA & $\begin{array}{c}2.586 \\
(66.202)\end{array}$ \\
\hline G4 & NA & $\begin{array}{l}-42.404 \\
(82.314)\end{array}$ \\
\hline NK & NA & $\begin{array}{c}63.201 \\
(91.321)\end{array}$ \\
\hline $\mathrm{vX}$ & NA & $\begin{array}{c}310.330 * * \\
(78.358)\end{array}$ \\
\hline WN & NA & $\begin{array}{c}2.075 \\
(70.484)\end{array}$ \\
\hline Constant & $\begin{array}{c}-379.966^{* *} \\
(141.611)\end{array}$ & $\begin{array}{c}64.990 \\
(292.615)\end{array}$ \\
\hline
\end{tabular}

Continued on next page. 
Table 8: Continued from previous page

\begin{tabular}{|c|c|c|}
\hline & Legacy-Legacy & LCC-LCC \\
\hline & (1) & (2) \\
\hline Variables & Coeff. & Coeff. \\
\hline IVAS & $\begin{array}{l}279.419^{*} \\
(132.052)\end{array}$ & NA \\
\hline IVCO & $\begin{array}{c}7.292 \\
(41.558)\end{array}$ & NA \\
\hline IVDL & $\begin{array}{c}-69.915 \\
(35.778)\end{array}$ & NA \\
\hline IVUA & $\begin{array}{l}-75.071 \\
(41.516)\end{array}$ & NA \\
\hline IVUS & $\begin{array}{l}113.125^{*} \\
(46.179)\end{array}$ & NA \\
\hline IVHA & $\begin{array}{c}325.217^{* *} \\
(94.299)\end{array}$ & NA \\
\hline IVB6 & NA & Omitted \\
\hline IVF9 & NA & $\begin{array}{l}-13.586 \\
(53.840)\end{array}$ \\
\hline IVFL & NA & $\begin{array}{l}-28.715 \\
(35.805)\end{array}$ \\
\hline IVG4 & NA & $\begin{array}{l}150.929 \\
(80.963)\end{array}$ \\
\hline IVNK & NA & $\begin{array}{c}27.052 \\
(54.457)\end{array}$ \\
\hline IVVX & NA & $\begin{array}{c}520.073^{* *} \\
(86.366)\end{array}$ \\
\hline IVWN & NA & $\begin{array}{l}-77.515 \\
(53.882)\end{array}$ \\
\hline Observations & 332 & 70 \\
\hline$R^{2}$ & 0.457 & 0.725 \\
\hline F-statistic for the IVs & 8.266 & 7.766 \\
\hline
\end{tabular}

$1 * * \mathrm{p}<0.01,{ }^{*} \mathrm{p}<0.05$.

${ }^{2}$ Standard errors are clustered robust, clustering by route.

${ }^{3}$ Dependent variable: Competitor Frequency. 
Table 9: LCC-LCC Regression

\begin{tabular}{lcccc}
\hline \hline & OLS & & 2SLS & \\
\hline \multicolumn{1}{c}{ Variables } & $(\mathbf{1})$ & $(\mathbf{2})$ & $\mathbf{( 3 )}$ & $\mathbf{( 4 )}$ \\
& Coeff. & Std.Err. & Coeff. & Std.Err. \\
\hline Log Competitor Frequency & -0.085 & $(0.226)$ & $0.762^{* *}$ & $(0.211)$ \\
Distance & $-0.001^{* *}$ & $(0.0002)$ & $-0.0003^{*}$ & $(0.0001)$ \\
Geometric Mean of Income above $\$ 75,000$ & 0.022 & $(0.031)$ & -0.006 & $(0.015)$ \\
Geometric Mean of Population & $0.021^{* *}$ & $(0.006)$ & 0.005 & $(0.004)$ \\
Leisure Route & -0.066 & $(0.141)$ & -0.019 & $(0.072)$ \\
Geometric Mean of Own \# Destination & $0.049^{* *}$ & $(0.010)$ & $0.033^{* *}$ & $(0.012)$ \\
Geometric Mean of Competitor's \# Destination & 0.004 & $(0.008)$ & $-0.021^{*}$ & $(0.008)$ \\
F9 & $0.564^{*}$ & $(0.246)$ & 0.212 & $(0.391)$ \\
FL & 0.078 & $(0.229)$ & -0.194 & $(0.336)$ \\
G4 & 0.041 & $(0.191)$ & 0.002 & $(0.194)$ \\
NK & 0.366 & $(0.307)$ & -0.203 & $(0.432)$ \\
VX & $1.489^{* *}$ & $(0.356)$ & $1.218^{* *}$ & $(0.218)$ \\
WN & -0.015 & $(0.229)$ & 0.093 & $(0.346)$ \\
Constant & $4.271^{* *}$ & $(1.218)$ & 1.414 & $(0.839)$ \\
Observations & 70 & & 70 & \\
$R^{2}$ & 0.630 & & - & \\
\hline \hline
\end{tabular}

$1 * * \mathrm{p}<0.01, * \mathrm{p}<0.05$.

${ }^{2}$ Standard errors are clustered robust, clustering by route.

${ }^{3}$ Dependent variable: Log Own Frequency.

${ }^{4}$ test of exogeneity: $\mathrm{p}=0.0004$

${ }^{5}$ test of overidentifying restrictions: Sargan chi-squared $(5)=2.875(\mathrm{p}=0.719)$ 
Table 10: LCC-LCC Regression with Linear/Average Specification

\begin{tabular}{lcccc}
\hline \hline \multicolumn{1}{c}{ Variables } & OLS & \multicolumn{2}{c}{ 2SLS } & \\
\hline & $(\mathbf{1})$ & $\mathbf{( 2 )}$ & $\mathbf{( 3 )}$ & $\mathbf{( 4 )}$ \\
& Coeff. & Std.Err. & Coeff. & Std.Err. \\
\hline Competitor Frequency & 0.067 & $(0.206)$ & $0.499^{* *}$ & $(0.152)$ \\
Distance & $-0.179^{* *}$ & $(0.059)$ & $-0.115^{* *}$ & $(0.033)$ \\
Average Income above $\$ 75,000$ & 3.702 & $(7.260)$ & -2.221 & $(3.922)$ \\
Average Population & $3.624^{*}$ & $(1.519)$ & $2.183^{*}$ & $(0.890)$ \\
Leisure Route & -13.058 & $(38.119)$ & -30.874 & $(23.140)$ \\
Average of Own \# Destination & $18.571^{* *}$ & $(2.940)$ & $19.704^{* *}$ & $(3.741)$ \\
Average of Competitor's \# Destination & -2.996 & $(2.661)$ & $-8.722^{* *}$ & $(2.874)$ \\
F9 & -28.366 & $(44.955)$ & -51.636 & $(54.126)$ \\
FL & -43.097 & $(38.285)$ & -51.401 & $(52.261)$ \\
G4 & $125.487^{* *}$ & $(44.007)$ & $166.373^{* *}$ & $(54.665)$ \\
NK & 2.732 & $(55.599)$ & -32.766 & $(67.908)$ \\
VX & $382.219^{* *}$ & $(105.172)$ & $349.018^{* *}$ & $(62.049)$ \\
WN & $-95.915^{*}$ & $(35.270)$ & $-106.018^{* *}$ & $(39.772)$ \\
Constant & -74.513 & $(233.723)$ & 102.444 & $(143.582)$ \\
Observations & 70 & & 70 & \\
$R^{2}$ & 0.700 & & - & \\
\hline \hline
\end{tabular}

$1 * * \mathrm{p}<0.01, * \mathrm{p}<0.05$.

${ }^{2}$ Standard errors are clustered robust, clustering by route.

${ }^{3}$ Dependent variable: Own Frequency.

${ }^{4}$ test of exogeneity: $\mathrm{p}=0.076$

${ }^{5}$ test of overidentifying restrictions: Sargan chi-squared $(5)=1.661(\mathrm{p}=0.894)$ 
Table 11: LCC-Legacy Regression

\begin{tabular}{lcccc}
\hline \hline & OLS & & 2SLS & \\
\hline \multicolumn{1}{c}{ Variables } & $(\mathbf{1})$ & $(\mathbf{2})$ & $\mathbf{( 3 )}$ & $\mathbf{( 4 )}$ \\
& Coeff. & Std.Err. & Coeff. & Std.Err. \\
\hline Log Competitor Frequency & $0.236^{* *}$ & $(0.079)$ & 0.093 & $(0.435)$ \\
Distance & $-0.001^{* *}$ & $(0.0001)$ & $-0.001^{* *}$ & $(0.0003)$ \\
Geometric Mean of Income above $\$ 75,000$ & $0.022^{* *}$ & $(0.008)$ & $0.025^{*}$ & $(0.011)$ \\
Geometric Mean of Population & $0.015^{* *}$ & $(0.002)$ & $0.015^{* *}$ & $(0.003)$ \\
Leisure Route & 0.062 & $(0.123)$ & 0.124 & $(0.219)$ \\
Geometric Mean of Own \# Destination & $0.034^{* *}$ & $(0.005)$ & $0.035^{* *}$ & $(0.005)$ \\
Geometric Mean of Competitor's \# Destination & -0.001 & $(0.002)$ & 0.000 & $(0.005)$ \\
F9 & 0.213 & $(0.152)$ & 0.220 & $(0.149)$ \\
FL & -0.094 & $(0.121)$ & -0.027 & $(0.233)$ \\
NK & 0.270 & $(0.186)$ & 0.281 & $(0.183)$ \\
SY & -0.041 & $(0.436)$ & 0.007 & $(0.446)$ \\
VX & 0.806 & $(0.457)$ & 0.952 & $(0.622)$ \\
WN & -0.174 & $(0.105)$ & -0.147 & $(0.129)$ \\
Constant & $3.038^{* *}$ & $(0.513)$ & 3.787 & $(2.305)$ \\
Observations & 170 & & 170 & \\
$R^{2}$ & 0.610 & & - & \\
\hline \hline
\end{tabular}

$1 * * \mathrm{p}<0.01, * \mathrm{p}<0.05$.

${ }^{2}$ Standard errors are clustered robust, clustering by route.

${ }^{3}$ Dependent variable: Log Own Frequency.

${ }^{4}$ test of exogeneity: $\mathrm{p}=0.737$

${ }^{5}$ test of overidentifying restrictions: Sargan chi-squared $(4)=5.851(p=0.211)$ 
Table 12: The Number of Contact Points

\begin{tabular}{cccccccccccccccc}
\hline & AA & AS & B6 & CO & DL & F9 & FL & G4 & HA & NK & SY & UA & US & VX & WN \\
\hline AA & 309 & 4 & 32 & 26 & 85 & 4 & 12 & 0 & 4 & 6 & 0 & 192 & 33 & 12 & 8 \\
AS & 4 & 76 & 4 & 6 & 2 & 4 & 0 & 0 & 6 & 0 & 0 & 30 & 4 & 4 & 34 \\
B6 & 32 & 4 & 122 & 10 & 54 & 0 & 16 & 0 & 0 & 8 & 0 & 20 & 14 & 12 & 18 \\
CO & 26 & 6 & 10 & 114 & 30 & 6 & 0 & 0 & 2 & 2 & 0 & 24 & 16 & 0 & 8 \\
DL & 85 & 2 & 54 & 30 & 347 & 13 & 100 & 0 & 8 & 22 & 2 & 43 & 55 & 8 & 48 \\
F9 & 4 & 4 & 0 & 6 & 13 & 113 & 22 & 0 & 0 & 0 & 0 & 82 & 8 & 0 & 64 \\
FL & 12 & 0 & 16 & 0 & 100 & 22 & 180 & 2 & 0 & 6 & 0 & 8 & 14 & 0 & 42 \\
G4 & 0 & 0 & 0 & 0 & 0 & 0 & 2 & 2 & 0 & 0 & 0 & 0 & 0 & 0 & 0 \\
HA & 4 & 6 & 0 & 2 & 8 & 0 & 0 & 0 & 14 & 0 & 0 & 4 & 2 & 0 & 0 \\
NK & 6 & 0 & 8 & 2 & 22 & 0 & 6 & 0 & 0 & 38 & 0 & 2 & 2 & 2 & 6 \\
SY & 0 & 0 & 0 & 0 & 2 & 0 & 0 & 0 & 0 & 0 & 2 & 0 & 0 & 0 & 0 \\
UA & 192 & 30 & 20 & 24 & 43 & 82 & 8 & 0 & 4 & 2 & 0 & 371 & 22 & 20 & 96 \\
US & 33 & 4 & 14 & 16 & 55 & 8 & 14 & 0 & 2 & 2 & 0 & 22 & 215 & 2 & 94 \\
VX & 12 & 4 & 12 & 0 & 8 & 0 & 0 & 0 & 0 & 2 & 0 & 20 & 2 & 26 & 4 \\
WN & 8 & 34 & 18 & 8 & 48 & 64 & 42 & 0 & 0 & 6 & 0 & 96 & 94 & 4 & 308 \\
\hline
\end{tabular}


Table 13: 2SLS Multimarket-Contact Regressions

\begin{tabular}{|c|c|c|}
\hline \multirow[b]{2}{*}{ Variables } & (1) & $(2)$ \\
\hline & Legacy-Legacy & LCC-LCC \\
\hline \multirow[t]{2}{*}{ Log Competitor Frequency } & $0.732 * *$ & $0.762^{* *}$ \\
\hline & $(0.098)$ & $(0.214)$ \\
\hline \multirow[t]{2}{*}{ Contact } & 0.001 & -0.001 \\
\hline & $(0.001)$ & $(0.005)$ \\
\hline \multirow[t]{2}{*}{ Distance } & $-0.0001^{*}$ & $-0.0003^{*}$ \\
\hline & $(0.00005)$ & $(0.0001)$ \\
\hline \multirow[t]{2}{*}{ Geometric Mean of Income above $\$ 75,000$} & $0.006^{*}$ & -0.007 \\
\hline & $(0.003)$ & $(0.013)$ \\
\hline \multirow[t]{2}{*}{ Geometric Mean of Population } & 0.001 & 0.005 \\
\hline & $(0.001)$ & $(0.004)$ \\
\hline \multirow[t]{2}{*}{ Leisure Route } & 0.041 & -0.025 \\
\hline & $(0.056)$ & $(0.056)$ \\
\hline \multirow[t]{2}{*}{ Geometric Mean of Own \# Dest. } & $0.017^{* *}$ & $0.034^{* *}$ \\
\hline & $(0.003)$ & $(0.013)$ \\
\hline \multirow[t]{2}{*}{ Geometric Mean of Competitor's \# Dest. } & $-0.013^{* *}$ & $-0.020^{*}$ \\
\hline & $(0.003)$ & $(0.009)$ \\
\hline \multirow[t]{2}{*}{ Constant } & $1.185^{*}$ & 1.426 \\
\hline & $(0.466)$ & $(0.816)$ \\
\hline Observations & 332 & 70 \\
\hline$R^{2}$ & 0.436 & 0.353 \\
\hline $1 * * \mathrm{p}<0.01, * \mathrm{p}<0.05$ & & \\
\hline
\end{tabular}




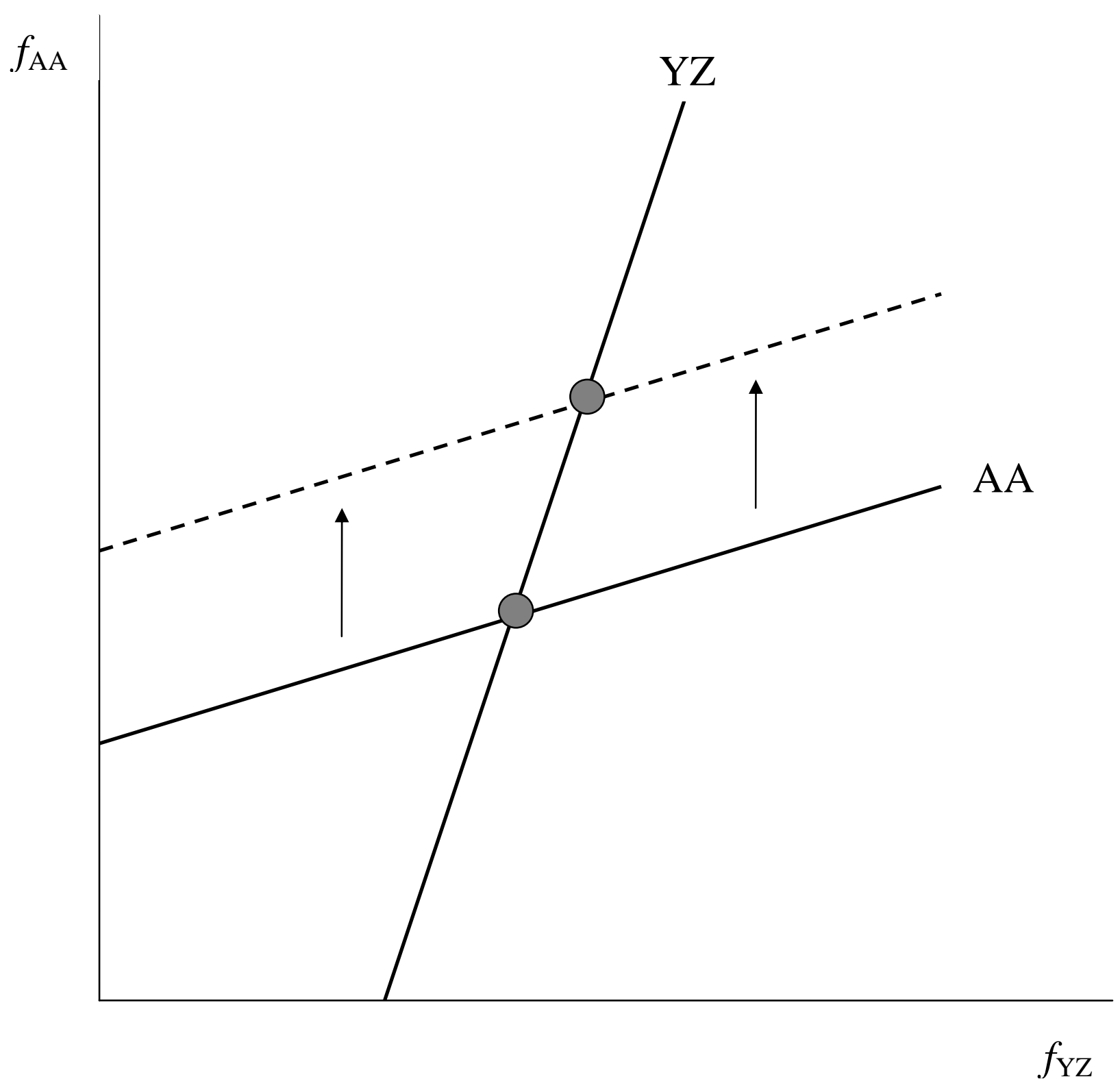

Figure 1: Shift of Reaction Function 


\section{References}

BERRY, S.T., 1994. Estimating discrete choice models of product differentiation. RAND Journal of Economics 25, 242-262.

Berry, S.T., Levinsohn, J., PAkes, A., 1995. Automobile prices in market equilibrium. Econometrica 63, 841-890.

Berry, S.T., Waldfogel, J., 2001. Do mergers increase product variety? Evidence from radio broadcasting. Quarterly Journal of Economics 116, 1009-1025.

Berry, S.T., JiA, P., 2010. Tracing the woes: An empirical analysis of the airline industry. American Economic Journal: Microeconomics 2, 1-43.

Bilotkach, V., Fageda, X., Flores-Fillol, R., 2010. Scheduled service versus personal transportation: the role of distance. Regional Science and Urban Economics 10, 60-72.

Bilotkach, V., 2011. Multimarket contact and intensity of competition: evidence from an airline merger. Review of Industrial Organization 38, 95-115.

Borenstein, S., Netz, J., 1999. Why do all the flights leave at 8 am?: Competition and departure-time differentiation in airline markets. International Journal of Industrial Organization 17, 611640 .

BrueCKNER, J.K., 2003. Strategic interaction among governments: an overview of empirical studies. International Regional Science Review 26, 175-188.

Brueckner, J.K., 2010. Schedule competition revisited. Journal of Transport Economics and Policy 44, 261-285.

Brueckner, J.K., Lee, D., Singer, E.S., 2012. City-pairs vs. airport-pairs: A marketdefinition methology for the airline industry. Unpublished paper.

Cotterill, R.W., Putsis, W.P., 2000. Market share and price setting behavior for private labels and national brands. Review of Industrial Organization 17, 18-39.

Crawford, G.S., Shum, M., 2007. Monopoly quality degradation in the cable television industry. Journal of Law and Economics 50, 181-219.

Crawford, G.S., Shcherbakov, O., Shum, M., 2011. The welfare effects of monopoly quality choice: Evidence from cable television markets. Unpublished paper. 
D’Aspremont, C., Gabszewicz, J., Thisse, J.-F., 1979. On hotelling's stability in competition. Econometrica 47, 1045-50.

Dhar, T., Chavas, J.P., Cotterill, R.W., Gould, B., 2005. An econometric analysis of brand-level strategic pricing between Coca-Cola company and PepsiCo. Journal of Economics and Management Strategy 14, 905-931.

Dietz, R., 2002. The estimation of neighborhood effects in the social sciences: an interdisciplinary approach. Social Sciences Research 31, 539-575.

Draganska, M., Mazzeo, M., Seim, K., 2009. Beyond plain vanilla: Modeling joint product assortment and pricing decisions. Quantitative Marketing and Economics 7, 105146.

Dujardin, C., Peeters, D., Thomas, I., 2009. Neighborhood effects and endogeneity issues. In: Bavaud, F., and Mager, C. (eds). Handbook of Theoretical and Quantitative Geography, pp. 29-71. FGSE, University of Lausanne, Lausanne, Switzerland.

Evans, W.N., Kessides, I.N., 1994. Living by the "golden rule": Multimarket contact in the US airline industry. Quarterly Journal of Economics 109, 341-366.

FAN, Y., 2011. Ownership consolidation and product characteristics: A study of the U.S. daily newspaper market. Unpublished paper.

Gabszewicz, J.J., Thisse, J.F., 1979. Price competition, quality and income distribution. Journal of Economic Theory 20, 340-359.

KEDIA, S., 2005. Estimating product market competition: Methodology and application. Journal of Banking and Finance 30, 875-894.

LiAng, J.N., 1989. Price reaction functions and conjectural variations: An application to the breakfast cereal industry. Review of Industrial Organization 4, 31-58.

Lazzarini, S.G., Artes, R., Caetano, M.A.L., Moura, M.L., Goldberg, M.B., Silva, C.E., 2007. Does it pay to anticipate competitor reactions? Working Paper, Insper Instituto de Ensino e Pesquisa, Brazil.

Lindsey, R.,Tomaszewska, E.,1999. Schedule competition, fare competition and predation in a duopoly airline market. In: Oum, T., and B. Bowen (eds.), Proceedings of the Air Transport Research Group (ATRG). Institute of Aviation, University of Nebraska at Omaha.

Manski, C.F., 1993. Identification of endogenous social effects: The reflection problem. Review of Economic Studies 60, 531-542. 
Mazzeo, M., 2002. Product choice and oligopoly market structure. RAND Journal of Economics 33, 221-241.

Morrison, S.A., Winston, C., 1995. The evolution of the airline industry. Brookings Institution Press, Washington, D.C.

PAI, V., 2010. On the factors that affect airline flight frequency and aircraft size. Journal of Air Transport Management 16, 169-177.

Prince, J., Simon, D.H., 2009. Multimarket contact and on-time performance in the US airline industry. Academy of Management Journal 52, 336-354.

Reimer, J.J., 2004. Market conduct in the U.S. ready-to-eat cereal industry. Journal of Agricultural and Food Industrial Organization 2, 1-27.

Revelli, F., 2005. On spatial public finance empirics. International Tax and Public Finance $12,475-492$.

Schipper, Y., Nijkamp, P., Rietveld, P., 2003. Airline deregulation and external costs: A welfare analysis. Transportation Research Part B 37, 699-718.

Schipper, Y., Nijkamp, P., Rietveld, P., 2007. Deregulation and welfare in airline markets: An analysis of frequency equilibria. European Journal of Operations Reserach 178, 194-206.

Shah, N., Brueckner, J.K., 2012. Price and frequency competition in freight transportation. Transportation Research Part A 46, 938-953.

Shaked, A., Sutton, J., 1982. Relaxing price competition through product differentiation. Review of Economic Studies 49, 3-13.

ViCKner, S.S., Davies, S.P., 1999. Estimating market power and pricing conduct in a product-differentiated oligopoly: The case of the domestic spaghetti sauce industry. Journal of Agricultural and Applied Economics 31, 1-13.

Zou, L., Dresner, M., Windle, R., 2011. Many fields of battle: How cost structure affects competition across multiple markets. Journal of Transport Economics and Policy 45, 21-40. 


\section{Footnotes}

*We thank Miguel Alcobendas, Jiawei Chen, Philip Gayle, Darin Lee and Ethan Singer for helpful comments. However, any errors or shortcomings in the paper are our responsibility.

${ }^{1}$ Prior to airline deregulation, when price competition was not allowed, airlines were viewed as competing excessively in flight frequency. Although deregulation enabled airlines to compete more vigorously in fares, airlines appear to still compete in flight frequency, and frequency has indeed increased since the hub-and-spoke system expanded airline networks (see Morrison and Winston (1995)).

${ }^{2}$ The conjectural variation is criticized by game theorists because it introduces dynamics into a static model in a logically flawed fashion.

${ }^{3}$ For earlier non-structural empirical work on product quality, see Mazzeo (2002) and Crawford and Shum (2007).

${ }^{4}$ This mixture of parameters can be seen in the reaction function derived in the theoretical analysis below (eq. (11)).

${ }^{5}$ Other empirical papers on flight frequencies include Pai (2010), who explores the determinants of frequencies and aircraft sizes using a reduced-form approach, and Bilotkach et al. (2010), who focus primarily on the relationship between the frequency choice and trip distance, providing a theoretical model and empirical evidence. In other theoretical work, Shah and Brueckner (2012) extend the model of Brueckner (2010) to the case of freight transportation.

${ }^{6}$ While the slope of the reaction function derived in section 2 is nonzero, it would be possible in principle for a theoretical model to generate a zero slope even when a carrier takes account of its competitor's frequency. Therefore, strictly speaking, a zero slope for an empirical reaction need not imply the absence of strategic interaction. However, the most likely explanation for such a finding is that a carrier ignores its competitor's frequency in make its own choices.

${ }^{7}$ In work more closely related to the present exercise, Bilotkach (2011) studies the relationship between flight frequencies and multimarket contact in a reduced-form model, while Prince and Simon (2009) explore the impact of multimarket contact on flight delays and cancellations.

${ }^{8}$ This property means that the equilibrium where fares and frequencies are chosen simultane- 
ously is the same as the one with sequential choice.

${ }^{9}$ Beyond generating a reaction function, Brueckner's (2010) analysis is devoted to providing both comparative-static and welfare analyses of the equilibrium with an arbitrary number of firms, along with analysis of a free-entry equilibrium, where the number of firms adjusts to ensure zero profit.

${ }^{10}$ In particular, the need to exclude one LCC from among the competitor dummies in regressions where the competitors are LCCs (such as the LCC-LCC model) leaves only one instrument and an exactly identified equation, which cannot be subjected to the overidentification test (see footnote 14 below).

${ }^{11}$ An alternate approach would rely on city-pairs rather than airport-pairs. This approach could use the airport groupings for multiple-airport metro areas generated by Brueckner, Lee and Singer (2012). While the airport-pair approach is used for simplicity, this city-pair approach could be explored in further work.

${ }^{12}$ Frequency could still exceed the 20 threshold when entry or exit occurs midway through a month, creating a misleading quarterly frequency total, but this drawback cannot be addressed and thus creates a source of measurement error. Aside from entry and exit, most cases with 20 or fewer departures involve flight diversions or other irregular events, which lead to only a few flight operations.

${ }^{13}$ Note that exogeneity of the competitor's frequency cannot be rejected under this new specification.

${ }^{14}$ Observe that IVB6 (jetBlue) is also omitted from the list of intruments. With the competitor being an LCC by construction, the IV's would sum to one without such an omission.

${ }^{15}$ Exogeneity of the competitor's frequency is rejected at the 10 percent level.

${ }^{16}$ Recall that this regression uses only the LCC observations. With only one observation used per route, clustering is unneeded.

${ }^{17}$ Routes with 3 legacies or 3 LCCs are too few in number for these cases to be investigated. In the regressions, the average of the log frequency of the two competitors appears on the righthand side, as does the average of the competitors' hub-status measures. This specification follows from the assumption that the coefficients of the individual log frequencies and hubstatus variables are equal across the two competitors. 
${ }^{18}$ Allowing the contact variable to affect both the height and slope of the reaction function again yields insignificant effects.

${ }^{19}$ Solving for the reduced form, AA's dummy coefficient when it is carrier $-i$ in (15) (that is, the carrier whose frequency is being determined) is equal to $\eta_{A A} /\left(1-\delta^{2}\right)$, while its dummy coefficient when it is carrier $i$ (that is, the other carrier in the market) is equal to $\delta \eta_{A A} /\left(1-\delta^{2}\right)$. The $1 / \delta$ factor by which AA's frequency change exceeds that of its competitor (from the text) would thus be found by taking the ratio of the IVAA coefficient and the AA coefficients from the first-stage regression. Since AA is the default carrier, such coefficients are not estimated, but the same point would apply to any other carrier, say Alaska (AS). Thus, the effect of an increase in Alaska's dummy coefficient on its own frequency relative to the frequency of a duopoly competitor (which should equal $1 / \delta$ ) would be given by the ratio of the IVAS and AS coefficients in Table 8. This ratio is $279 / 176=1.58$, which is very close to 1.6 or $1 / \delta$. While the analogous ratios for US Airways and Hawaiian Airlines are 1.36 and 1.51, respectively, the ratios for the other legacy carriers are not at all close to 1.6, as they should be in theory, a result that is due to the reliance on statistical, rather than algebraic, procedures to generate the reduced form. 